Note: This is a copy of the manuscript of a plenary lecture pre-

sented at the XI International Congress of Crystal lography in Warsaw, Poland, August 3-12, 1978.

\title{
MASTER
}

CRYSTALLOGRAPHIC CONTRIBUT IUNS TO THE ENERGY PROBLEM

M. K. Wilkinson

\begin{abstract}
By acceptance of this article, the publisher or recipient acknowledges the U.S. Gpyernment's right to retain a nonexclusive, royalty-free license in and to any copyright covering the article.
\end{abstract}

SOLIE STATE DIVISION

OAK RIDGE NATIONAL LABORATORY

Operated BY

UNION CARBIDE CORPORATION

Contract No. W-7405-eng-26

for the

DIVISION OF MATERIALS SCIENCES

UNITED STATES DEPARTMENT OF ENERGY

OAK RIDGE, TENNESSEE 


\section{CRYSTALLOGRAPHIC CONTRIBUTIONS TO THE ENERGY PROBLEM}

The subject that I have been asked to address is one which is becoming a very important challenge for crystallographers. There is certainly no need for me to emphasize to this audience that there is a serious shortage of energy in the world, that it appears to be growing more serious with time, and that. the problem is not going to be solved easily and quickly. The primary question of concern to us is, "What can we as crystallographers do about it?"

Many of you have already given a lot of thought to this subject and have even redirected your research accordingly. I doubt that 1 can add much to your ideas. However, many others of you have probably thought very little about the types of contributions that you can make, and I hope that my comments wlil help to stimulate some of you into becoming more involved.

of course, the reason that crystallographers can make important contributions to the energy problem is because crystallographers obtain fundamental information on materials, and every advanced energy technology is materials limited. Therefore, our job, in principle, is quite straightforward. We need to use our experimental facilities and our skills in providing information that will lead to the development of new materials that are required.

A I ittle over a year ago the United States Energy Research and Development Administration (which is now part of the Department of Energy) conducted a series of nine workshops in materials science. The purpose was to assess the needs for research on inergy-related materials. The broad topics covered in these nine workshops are shown on my first slide. Each workshop was attended 
by leading scientists within the United States with special expertise in these topics and by scientists and engineers closely associated with the energy technologies. Of course, Number 3, the Workshop on X-ray, Neutron, and Electron Scattering, could very well have been called "the Workshop on Crystallography." This Workshop was held at the Oak Ridge National Laboratory, and many thoughts that I want to leave with you are a result of discussions held at that time. One of the objectives of the workshops was to determine the types of materials research needed for various advanced energy. technologies. My next slide gives you an idea of the wide variety of materials problems that exist.

\section{SLIDE 2 - Materials Research Required by Energy Technologies}

On the left are broad areas where materials with better properties could be beneficial to the energy technologies shown across the top. I do not wish to imply that this is a complete list; I merely want to point out that every energy technology requires research and development on many different types of materials. Furthermore, crystallography can play a very important role in the development of these materials. To irdicate this fact, 1 am going to show you another chart with these same classes of materials research along with important properties that can be determined by crystallographic investigations. This is shown on my next slide.

\section{SLIDE 3 - Materials Research Requiring Crystallographic Studies}

It should certainly be apparent from this chart that there are many classes of energy-related materials where crystallograpnic information can be very important in materials development. These crystallographic investigations 
are grouped according to properties of materials, which was the method used in the workshop. They involve every possible type of crystallography: struture investigations under a variety of external conditions, such as temperature, pressure, and atmosphere; elastic, inelastic and quasielastic neutron scattering; small-angle neutron and $x$-ray scattering; electron microscopy; and so forth.

It is doubtful that any other branch of science can compare with crystailography in providing such a wide variety of important information on energyrelated materials. And, of course, the reason is one that we all recognize- in order to predict and develop new materials with special properties, it is necessary to understand those properties on an atomic scale in existing materials.

It is obviously not possible to go through this chart item by item and try to tell you about the types of research that are necessary. Instead, I shall merely try to guide your thoughts by pointing out some of the research investigations that have already been performed and others that are in progress. I have chosen four of these areas to discuss: radiation effects, catalysts, electrolytes, and superconductors. The particular examples that I shall mention were chosen not only because of their importance, but because they cover a wide variety of crystallographic techniques. Of course, many other examples would have been equally approprlate, and I want to apologize at the beginning to those of you who have done important work that I will not have time to discuss.

First of all, let's look at this area of radiation effects; this is extremely important, of course, in the construction of fission and fusion reactors, and it is also important in MHD devices. I shall limit my remarks 
today to radiation effects in metals. Other techniques, such as electron spin resonance and optical spectroscopy, are very powerful tools for investigating radiation effects in insulators, but they cannot be used for such studies in metals. Most of the information, therefore, has to come from crystallographic investigations.

When metals are irradiated with energetic particles, atoms are displaced from lattice positions into interstitial positions, and the resulting Frenkel pair, interstitial and vacancy, is the basic defect produced by radiation damage. These defects, clusters of them in the form of dislocation loops, and voids pose serious materials problems in reactor design, because they are responsible for metal embrittlement, creep, swelling, and phase instabilities.

Although the production of self interstitials and vacancies in metals has been known for about 30 years, the configuration of the interstitial has been unknown. My next slide shows six possible self-interstitial configurations

SLIDE 4 - Six Self-Interstitial Configurations in a F.C.C. Lattice

for a face-centered cubic lattice. In the split interstitial configurations the displaced atom forms a dumbbell with another lattice atom so that the dumbbell is centered at a lattice position and is oriented along the directions - indicated. These four configurations on the right were ruled out fairly easily by diffuse $x$-ray scattering measurements, actually Huang scattering, which I will discuss in more detail later. However, there was difficulty in determining whether the octahedral or [100]-split interstitial was the correct one. The proper ceifiguration has been determined recently through very precise measurements of the diffuse $x$-ray scatfering in the region between Bragg 
reflections. With such measurements it is possible to obtain information on the atomic configuration and on lattice displacements very close to the defects. My next slide shows results obtained by Haubold and his associates at Jïlich,

\section{SLIDE 5 - Haubold's Results on Copper Interstitial}

Germany for copper. The copper specimen was irradiated at $4^{\circ} \mathrm{K}$ to contain about 0.03\% Frenkel pairs, and the measurements were performed at $4^{\circ} \mathrm{K}$ to prevent annealing effects from occurring. The figure at the left shows the measured intensity contours in a region of reciprocal space containing the (III) and (200) reciprocal lattice points. The other two figures give calculated contours for the [100]-split and octahedral configurations. Comparison with Hauboid's data shows clearly that the [100]-split interstitial is the one that exists. These measurements are particularly notable because of the relatively large Compton scattering and temperature diffuse scattering that were present. The data were obtained using a $100 \mathrm{KW}$-rotating anode $x$-ray tube.

Unlike this type of diffuse scattering information, which is obtained from measurements between the Bragg peaks, by measuring the diffuse scattering near the Bragg peaks, usually referred to as Huang scattering, it is possible to obtain information on the long-ranging part of the strain fields due to the Interstitials. This type of scattering is shown on the next slide. These are data for aluminum, and as you see in the figure on the left,

\section{SLIDE 6 - Huang Scattering from Al uminum}

this Huang scattering is relatively large compared to the temperature diffuse scattering. From this type of measurement around various Bragg peaks, information 
on the symmetry of lefrots and defect clusters can be obtained. In fact, because Huang scattering measure: the long-ranging strain fields, it is extremely sensitive to the iormation of dafect clusters. If there are several separate interstitlals scattering incouerently, the intensity is proportional to the number of interstitials; however, if these Interstitials cluster and scatter coherently, the intensity is proportional to the square of the number of interstitials. This effect was very important in studying the recovery of radiation damage by thermal annealing. Notice this figure on the right showing the thermal annealing of aluminum. The electrical resistivity decreases monotonically through this stage of annealing, which indicates a monotonic decrease in the number of Frenkel pairs. However, the Huang scattering first decreases and then increases dramatically. This effect, which was observed by Ehrhardt and his associates at Jilich, is due to the clustering of interstitials in the temperature range above $40^{\circ} \mathrm{K}$. It clearly shows that the interstitials migrate freely at these temperatures and thereby resolved a controversy on interstitial migration which had existed for about 20 years. You notice from both the Huang scattering and resistivity data that essentially all interstitials have been annealed out of aluminum by about $300^{\circ} \mathrm{K}$-- this has been accomplished by migration of the vacancies.

In general, for neutron damage in metals the only defects remaining above room temperature are clusters of interstitials and vacancies, which are in the form of small dislocation loops. From measurements of the Huang scattering very near to the Bragg peaks, it is possible to extract information on the concentration and size distribution of these loops. The next slide shows results 
that were obtained at Dak Ridge National Laboratory by Larson and his associates on the size distribution of interstitial and vacancy loops in neutron-irradiated copper at room temperature. For comparison, measurements by transmission. electron microscopy are also shown. The comparison is quite reasonable, and it now appears that better quantitative data can be obtained, particularly for the smallest loops, by the $x$-ray technique. A more detailed analysis of this. .. Huang scattering should be able to give separate size distributions for the vacancy loops and the interstitial loops that exist simultaneously in the crystals, but such an analysis was not attempted in the data shown here.

A very serious radiation damage problem that was encountered recently is the formation of voids in metals irradiated to a very high dose at elevated temperatures. This problem has been studied by both small angle $x$-ray and neutron scattering, and it will require much more research in the future. My next slide shows some small angle neutron scattering results. On the left are

\section{SLIDE 8 - SANS of Voids in Irradiated Aluminum}

intensity measurements obtained by Child and Spooner at Oak Ridge, taken on a single crystal of irradiated aluminum with the neutron beam parallel to the [100] direction. You notice the very anisotropic distribution of the scattering. On the right is a size distribution of voids that was measured in a similar sample of irradiated aluminum by Hendricks, Shelton and Schmatz in Jülich, Germany. This distribution, which shows most of the voids with a diameter about $400 \AA$, was obtained from data at very small angles where the scattered intensity was isotropic. They also studied the void morphology by examining the anisotropy of the scattering at larger angles and showed that the voids have a truncated octahedral shape. These types of investigations are continuing; it is necessary 
to know the size distribution and morphology of the voids as a function of Irradiation variables in order to determine the mechanisms for vold formation and growth. Of course, electron microscopy plays a central role in these radiation damage studies, but diffuse scattering investigations are necessary in supplying complementary information.

I shall now turn to a second class of materials research -- electrolytes. There has been much interest recently in the use of high energy densliy batteries for load leveling utility systems, for electric vehicles, and for fuel cells. The possibility for major advances in battery systems can be seen by consideration of data on my next slide.

SLIDE 9 - Theoretical Spacific Energy vs Equivalent Weight

Here, the theoretical specific energy, i.e., the energy that can be stored per unit weight, is plotted against equivalent weight for a number of possible electrochemical couples. The $\mathrm{Pb}_{-} \mathrm{PbO}_{2}$ couple for the common lead-acid cell is near the bottom of the figure, and it is quite spparent that much more energy can be stored per unit weight with other systems. However, the best chemical combinations involve very reactive constituents so that an aqueous electrolyte would not be feasible. About 10 years ago, Kumner and Weber of the Ford Motor Company produced a radically different type of electrochemical ceil, in which the electrolyte was a solid, called $\beta$-alumina. This solid was stable in the presence of boith sodium and sulfur, which served as electrodes. Furthermore, even though it has a melting point over $2000^{\circ} \mathrm{C}$, it is an ion-conducting electrolyte with the sodium ions moving almost as fast as if it were a liquid. Crystal lography has made major contributions to the development of sol id electrolytes by structural investigations, which have helped to explain the 
high conductivity and have provided a basis for predicting new electrolytes. Various systems hàve been studied, which include complex silver compounds, titanates, niobates, and a variety of intercalation layer-type compounds. The conductivity of some of them is shown on my next slide. Many of these materials

\section{SLIDE $10-\log$ o vs $1000 / T$ (Ionic Conductivity)}

have fairly complicated crystal structures, and all of them provide a mechan Ism whereby ions move easily between lattice sites. I am going to discuss $\beta$-alumina, because it is a very pretty illustration of the use of crystallography in providing an understanding of the transport properties of a materlal. Furthermore, it will undoubtedly be one of the first solid electrolytes used in commercial batteries.

The structure of $\beta$-alumina is iridicated on my next slide. The idealized

\section{SLIDE 11 - Spinel Block of $\beta$-alumina}

composition is shown at the top, and there are many isomorphs. The sodium can be replaced by other monovalent ions, and the al uminum can be replaced by gallium or iron. The general features of this structure were solved by Bragg in 1937 and by Beevers and Ross in 1938. They showed that the compound crystallizes in a hexagonal unit cell, composed of spinel-like blocks of aluminum and oxygen that are separated by Na-O layers in mirror planes. In the space group for this structure there are three sites for the $\mathrm{Na}$ in a $\mathrm{Na}-\mathrm{O}$ layer: the so-called Beevers-Ross site where they placed the $\mathrm{Na}$, and the anti BeeversRoss site and mid-oxygen position, which they considered vacant. As it turns out, the $\mathrm{Na}$ is not restricted only to this Beevers-Ross position, and that is the reason for the high conductivity. My next slide shows the distribution of 
SLIDE 12 - Distribution of $\mathrm{Na}$ in B-alumina at $20^{\circ} \mathrm{C}$

$\mathrm{Na}$ in the Na-O layer at $20^{\circ} \mathrm{C}$. These are fairly recent neutron diffraction data by Roth and Reidinger which were obtained at Brookhaven National Laboratory. In addition to $\mathrm{Na}$ at the Beevers-Ross site; it also exlsts at the mid-oxygen position, which are these three equivalent sites, and there is a little at the anti Beevers-Ross position in the center of the three mid-oxygen positions. Actually, this distribution between the three different types of sites varles with temperature, and it is different for other ions in some of the isomorphs. However, it is certainly apparent that such a disordered structure permits rapid diffusion of $\mathrm{Na}$ in this plane.

It has been possible to proceed much farther with crystallographic techniques and to determine the main factors that control the ionic conductivity. Many different groups have worked on the $\beta$-alumina system, but I would I ike to mention especially the large contributions by Roth and his assoclates in the United States and by Guinier, Comes and their associates in France.

First of all, the ideal composition shown here never exists -- there is always about $20 \%$ excess sodium, all of which is in these Na-O layers. Well, what about charge compensation for the excess sodium? is it accomplished by Al vacancies or by excess oxygen? Roth and Reidinger have shown that charge: compensation is produced by excess oxygen and that this excess oxygen causes a unique defect in the spinel block. This determination has recently been confirmed by the French workers. The excess oxygen is in the mid-oxygen posltion, and the next slide shows the defect that is produced. This Aluminum atom 
moves into an adjacent interstitial position directly above the mid-oxygen position, thereby creating a Frenkel defect, i.e., an Eluminum vacancyInterstitlal pair. By symmetry, this Frenkel defect is attached through the oxygen atom to its mirror image in the next spinel block. These defects help to stabilize the $\beta$-alumina structure by relaxing stresses caused by the small highly charged aluminum ions.

of course, it is apparent that these defects affect the mobility of sodium ions in the conduction.plane. In fact, manipulation of the defects by sample preparation or incorporating impurities should result in modified transport properties. Consequently, this is a situation in which crystallography not or.ly explained the important physical property of a material but also showed how that property might be controlled. Actually, such a structural modification is exactly what occurs in another form of $\beta$-alumina, the so-called $\beta^{\prime \prime}-a l u m i n a$. The two structures are very similar as shown on my next slide.

SLIDE 14 - Comparison of $\beta$-alumina and $\beta^{\prime \prime}-$ alumina

Whereas $\beta$-alumina is hexagonal and consists of two spinel blocks, $\beta^{\prime \prime}-$ al umina is rhombohedral and consists of three spinel blocks. Aside from that, the general feafures of the two structures are almost identical. However, the B" structure does not have any Frenkel defects and it does not have the excess sodium and oxygen found in the Na-O layer of $\beta$-alumina. Furthermore, single crystals cannot be prepared without adding a third cation, eg, $\mathrm{Mg}^{+2}$. The replacement of the small triply-charged $\mathrm{Al}^{+3}$ by a larger ion with smaller charge reduces the lattice strains. Since this structure does not have blocked paths in the conduction plane, you might expect a larger ionic conductivity. 
That is exactly what is found; $B^{\prime \prime}-a l$ umina has a conductivity several times higher than B-alumina and may turn out to be a more useful material as a solid electrolyte.

The third research area that I shall discuss concerns crystallographic investigations of another type of conductivity, namely superconductivity. Superconducting materials are needed to produce high field magnets in fusion reactors and magneto-hydrodynamic devices, they have potential in energy storage, and they are important in the conservation of electrical energy. There are two main objectives in present superconductivity research-- to obtain superco fuctors with higher transition temperatures and to obtain superconductors which can transport higher currents. Crystallographic investigations are involved in both types of research.

One interesting crystallographic investigation on high temperature superconductors is the measurement of phonon dispersion curves by inelastic neutron scattering. My next slide is an illustrative example. These are

SLIDE 15 - Longitudinal Acoustic Modes in TaC and $\mathrm{HFC}$

dispersion curves for the longitudinal acoustic modes in TaC and $\mathrm{HfC}$ that were obtained by Smith and Glaser at Oak Ridge in 1970. HfC does not become superconducting down to about $1^{\circ} \mathrm{K}$, and the dispersion curves for HfC have a normal behavior. On the other hand, TaC is a relatively high temperature superconductor with a transition at about $10^{\circ} \mathrm{K}$, and you notice these oscillations in the dispersion curves. These are isomorphous compounds in which the only apparent difference is the number of valence electrons. Therefore, it is believed that these oscillations are associated with the strong electronphonon interaction required for superconductivity. The phonon dispersion 
curves for other high temperature superconductors al so show this behavior. Much theoretical work has been done, but there really is not a completely satisfactory explanation of these oscillations at the present time. However, it should be mentioned that theoreticians are making definite progress in this area; recent calculations of the phonon line-widths due to the electron-phonon interaction agree very well with experimental measurements.

Another area of crystallographic research associated with high transition temperatures concerns the effect of nuclear radiation on superconducting materials. My next slide shows the dramatic decrease in the superconducting

\section{SLIDE 16 - Superconducting Transition vs $\phi$}

transition temperature of A-15 compounds as a function of irradiation with high energy neutrons; only $\mathrm{MO}_{3} \mathrm{Os}$ shows a relatively small effect. These are recent data of Cox, Sweedler, and Moehlecke of Brookhaven National Laboratory, who also showed that similar changes are found in some of the other superconducting parameters. They have made careful measurements of transition temperatures, long-range order parameters and lattice constants on many irradiated and unirradiated samples. From these detailed measurements, they have concluded that the principal reason for this change in $r_{c}$ and in the other parameters is a disorder due to the two types of atoms changing sites. My next slide shows some of their data on the variation of the

$$
\text { SLIDE } 17-T_{c} \text { VS S }
$$

transition temperature with the long-range order parameter S. You notice, of course, that $\mathrm{T}_{\mathrm{C}}$ for $\mathrm{Mo}_{3}$ Os is relatively insensitive to site-exchange disorder. There are two sets of data for $\mathrm{Mo}_{3} \mathrm{Os}$; in the samples of Flïkiger, et al., 
disorder was introduced by quenching, whereas in the samples of Sweedler. Cox and Moehlecke, it was introduced by irradiation. These experiments also showed that annealing can restore the original $T_{c}$, lattice parameter, and long range order. Consequently, from a practical viewpoint, it may be possible to use these materials in a radiation environment, if provision ce'l be made for periodic anneal ing.

The other important research in superconductivity involves obtaining higher currents in Type II superconductors, which are the important superconductors from a technological viewpoint. When these materials are placed in an external magnetic field and the field is increased above a specific value, the magnetic field is no longer repulsed from the superconductor but starts to penetrate it. The magnetic field within the superconductor exists as quantized flux lines called fluxoids, which are arranged in a two-dimensional lattice. Cribier, Jacrot and their associates at Saclay showed in 1964 that these fluxoids can be observed by neutron diffraction. My next slide shows

SLIDE 18 - Microscopic Field Distribution of Fiuxoids in Nb

the mlcroscopic field distribution that was determined by Weber, Schelten and Lippmann at Jïlich for a sample of superconducting niobium. At the bottom is the cross-sectional view perpendicular to the two-dimensional fluxoid lattice, with contour lines representing the field distribution. The top view shows the intensity of the magnetic s:eld in three dimensions. You notice that the two-dimensioral lattice is triangular; this is the normal symmetry, but it can take other regular forms for various types of crystal symmetry if there is a strong interaction with the crystal lattice. The nearest 
neighbor distance depends on the temperature and field, but it is alvays quite large-mof the order of $2000 \AA$--so that the experiments must be performed at very small angles. One of the important results of the experiment shown in this slide was the determination of the distribution of magnetic field within a fluxoid; this distribution, of course, was determined by precise form factor measurements.

A practical goal is to understand the motion of these fluxoids, which occurs at high fields and currents. They start to move across the superconductor, dissipating energy and causing the material to become non-superconducting. If this motion can be pinned, higher currents can be obtained.

A large amount of the neutron scattering work on fluxoid lattices has been performed at Jülich by Schelten, Schmatz, Ul Imaier; Lippmann and their associates. They have performed many types of experiments involving fluxoid morphology, magnetic field distribution and the effects of transport currents on the fluxoid lattice. Some very important results have come from their investigations. In one important investigation, they showed that when the fluxoid lattice moves at high currents, it moves as a periodic lattice. In another very difficult experiment, they measured the distribution of currents within a superconductor and showed that this distribution was consistent with the critical field model of superconductivity. They have also investigated the bending of $\mathrm{flux}$ I ines due to $\mathrm{Nb}_{2} \mathrm{~N}$ precipitates.

More recently, investigations have been initiated at Oak Ridge by Christen, Tasset and Thorel using a very high resolution double-crystal technique to obtain very precise information on the fluxoid behavior. These measurements have revealed exact!y how the fluxoid lattice is formed with increasing field and how it disappears with decreasing fiels. They have recently obtained a 
very unexpected result which is shown on my next slide. These data show the

\section{SLIDE 19 - Misalignment of Fluxoid Lattice}

misalignment of the fluxoid lattice with respect to applied magnetic field, when the field was applled parallel to various crystal directions of Nb. Prior to these measurements it had always been assumed that the fluxoid lattice was exactly parallel to the applied field, but as you see here for $\mathrm{Nb}$, there is usually some misalignment. Such a misalignment could be quite serlous in the A-15 compounds where the interaction between the fluxoid lattice and crystal lattice is expected to be more anisotropic than in Nb. The fourth area of crystal lographic research on energy-related materials, which I have chosen, concerns catalytic materials. Of course, catalysts are important in a variety of technologies, but they are particularly important in the gasification and liquefaction of coal. For those of you totally unfamiliar with catalysts, let me say that there are many different types and my next slide shows some illustrative examples. This is by no means a complete

\section{SLIDE 20 - List of Types of Catalysts}

Iist; I merely want to point out the wide variety of both simple and complex. materials that can be used as catalysts. Crystal structure investigations have provided a lot of important information, particularly on these complex systems, but I shall not discuss any structure studies. I shall limit my remarks to some crystallographic investigations that have been made on the simple metal catalysts.

In understanding catalytic activity, it is essential to know the details. of the surfaces that are involved. As you know, the field of surface science 
has really only become quantitative during, the past 5 years or so. Sol id surfaces can now be-reproducibly prepared in high vacuum and studied by many techniques, such as LEED, Auger spectroscopy, energy loss spectroscopy, positive ion channeling spectroscofy, and so on. We now know that the stable surface can be characterized by one of several ordered surface structures which depend on the symmetry of the substrate. Furthermore, the varlous slirface structures may have only slightly different free energies of formation, so that one surface structure may change into another more stable one as the temperature or chemical environment is changed. An illustration of this effect is shown on my next slide. These are data obtained at Dak Ridge

\section{SLIDE 21 - Ro-Ordering of Au Surface}

by Jenkins, Zehner, and Noonan; which show how the structure of the (110) surface of gold varies with temperature. On the left is the simplest structure; it is one which is Identical to the bulk, but it exists in gold only above $475^{\circ} \mathrm{C}$. The more complicated structure on the right exists at room temperature. Positive lon channe! ing measurements by Appleton and his associates have shown that the first layer of this structure is relaxed inward toward the second layer by about 10\%. This is a completely reversible process with temperature and obviously plays an important role in surface-related phenomena such as catalysis.

The physical geometry of the surface is al so closely associated with catalytic activity as was shown recentiy by Somorjai and his students at the University of Callfornia at Berkeley. They carefully prepared surfaces of a platinum single crystal so that the surfaces were microscopically flat but contained atomic steps. Such a surface is shown schematically on my next slide. They found that a stepped surface showed considerable catalytic activity 


\section{SLIDE 22 - Schematic Representation of Stepped Surface}

whereas an unstepped surface was essentially inactive. In fact, a stepped surface seemed to show selectivity to different hydrocarbon reactions, which • was dependent on the step periodicity.

Information on the morphology of supported metal catalysts is also Important in understanding catalytic activity. Altnough the particle size distribution can be obtained by electron microscopy, it is a tedious technique to obtain good statistical accuracy. Information on the area of catalysts exposed can be obtained from chemisorption measurements, but sometimes these results are unrel lable. Therefore, $x$-ray scattering techniques have been applied to these problems. Small angle x-ray scattering measurements have been developed particularly by Renouprez, Imelik, Gallezot and their associates. These measurements show promise, but great care must be taken to make corrections for scattering from the pores of the support. One method is to el iminate this scattering by filling the pores with a fluid that possesses the same electronic density as the support.

In very recent work in the United States, Cohen and Sashital, working as part of a group Including catalytic chemists, have studied platinum: catalysts supported by sillica. They have shown that a large amount of: Information can be obtalned by very careful Fourier analyses of Bragg reflections. They were able to determine the existence of microstrains in the particles and to measure the crystallite sizes in a number of crystallographic directions. The next slide shows some of their data. Here you see data on

SLIDE 23 - Particles Sizes $\langle L\rangle_{h k l}$ in the $\langle h k l\rangle$ Directions and Percentages Exposed 
catalysts prepared in four different ways, with two specimens under each type of preparation. For the first method of preparation the platinum particles were comparable in size to the pores in the silica, and these particles showed microstrains. These other three preparations produced strain-free particles, and you notice that for each of them the platinum particle sizes In the various crystallographic directions are comparable. This means that the platinum particles are nearly spherical and not cubic as had been frequently assumed. The last two columns compare the percentages of particles exposed, as measured by $x$-ray scattering and by chemisorption; you notice that the " agreement is good. Cohen, Sashital, and their associates al so showed that the logarithm of the root-mean-square amplitude of vibration increased wlth the percentage of atoins exposed and that a correlation existed between the amplitudes of vibration and catalytic activity, which is shown on my next slide. The turnover number is defined as the molecules reacted per surface

\section{SLIDE 24 - Correlation of Catalytic Activity}

atom per second for three different hydrogenation processes--the hydrogenation of cyclopropane, methylcyclopropane, and propene. You notice the linear relationship between the catalytic activity and the root-mean-square vibrational amplitude obtairied from the $x$-ray data. Such a correlation suggests that the catalytic activity is strongly influenced by the surface phonons of the catalyst. In other very recant investigations at the University of. Kentucky, De Angel is and his associates have shown that careful analysis of the profile of a single $x$-ray peak can determine average particle size, miarostrain, and the particle size distribution. 
Before leaving the subject of catalysis, I would like to mention an exploratory experiment using synchrotron radiation by Lytle, Via, and Sinfelt at Stanford University, which appears to be a promising method for future investigations. My next slide shows some of their data on platinum catalysts

\section{SLIDE 25 - EXAFS Data on Plat'num}

supported on silica. On the left of the slide are EXAFS data taken at $100^{\circ} \mathrm{K}$. $K$ is the photoelectron wave length, and $X(K)$ represents normallized fluctuations in the absoiption coefficient measured between the $L_{3}$ and $L_{2}$ absorption edges. At the right are the corresponding Fourier transforms, which give the distances from a platinum atom to surrounding atoms. The top data are for a Pt standard, the center for a $10 \%$ platinum catalyst, and the bottom for a $1 \%$ platinum catalyst. From the peak intensities it was possible to determine that the surface atoms have a higher vibrational amplitude than the bulk atoms and that the surface atoms have an average coordination number of 7 compared to 12 for atoms in the bulk platinum.

This concludes the remarks that I planned to make about crystallographic Investigations in four important areas of materials research related to energy technologies. Of course, there are many other areas that I could have,chosen to discuss. There have been a number of important crystallographic investigations of high temperature materials, salt hydrates for use in energy storage, amor phous materials, polymers, and even coal itself. Moreover, the properties of metal hydrides have been studied at many reactor centers throughout the world. These hydrides could be very important in plans to use hydrogen as a primary fuel, because they offer great possibilities for the storage and transport of hydrogen cheaply and safely. of course, neutron crystallography 
offers an excellent method to determine information on bonding and diffusion mechanisms in these hydrides, which is necessary to develop optimum systems. Particularly important investigations on metal hydrides have been performed in Denmark by Andresen and his associates, in Germany by Springer, Alefeld, and Richter, and in the United States by Rowe and Rush of the Nationai Bureau of Standards and by Flotow and Sköld of Argonne National Laturatory. It has obviously not been possible for me to discuss all of the important crystallographic investigations associated with materials for energy teclinologies, but I believe that the examples I have chosen are representative of the types of studies that can be performed.

In closing this lecture, I want to say just a few words about the future. If you as crystallographers want to make contributions that will help in the solution of the energy problem, what can you do? I wish that it were possible to I ist just a few crystallographic problems and tell you that their solutions would end our concerns about energy. Unfortunately, there is no such I ist! It is only possible to show again on the next slide the chart that I showed

\section{SLIDE 26 - (Repeat of Sl ide 3)}

earlier. These are the important types of crystallographic information that can be obtained in areas of research, which are needed to develop new materials required by the advanced energy technologies. It is obvious that crystallography is essential in the solution of these materials problems. Furthermore, as the existing problems are solved and new problems develop, crystallography will continue to play a dominant role in solving them.

There have been many recent developments in both equipment and techniques that can be applied to crystallographic problems. These new facilities and 
techniques are opening many new research areas for crystallographers. My next slide lists some of the new research directions that could be very

\section{SLIDE 27 - New Research Directions}

significant in helping to understand various physical properties of materials.

of course, neither the new techniques nor the new research areas can help to solve practical materials problems unless crystallographers know what the major problems are. We cannot do this by isolating our interests and our research. In order to make our best contributions, we must interact closely with other scientists.

In an excellent article in Physics Today about three years ago, Professor Guinier pointed out that the future of crystallography is bright-- that there is much exciting work for crystallographers to do, but that it should be done in collaboration with chemists, biologists and especially with solid state physicists. He pointed out the need to study defects in the long range periodicity of the crystal, because these defects are frequently connected to the important physical properties of materials. I wish to emphasize his remarks! For those of you who wish to help solve materials problems related to advanced energy technologies, it is essential that you follow this advice. There are many areas in materials science where important new crystallographic information can be obtained, but it is necessary that you interact closely with materials scientists working in these areas. They need the results you can outain from crystallographic investigations; you need their guidance in the choice of problems and their physical property measurements. You must use your expertise in trying to understand huw structural characteristics-moth long range periodicity and the lack of it--affect materlals properties. This 
Information is not only very important from a scientific viewpoint, but it is essential in the prediction and development of new materlals with special properties. 
DOE MATERIALS SCIENCES WORKSHOPS, 1977

WORKSHOP

1. ELECTRONIC, MAGNETIC OPTICAL AND THERMAL PROPERT..$S$

2. SURFACE SCIENCE

3. X-RAY, NEUTRON AND ELECTRON SCATTERING

4. LOW TEMPERATURE RESEARCH AND SUPERCONDUCTIVITY

5. PHASE TRANSFORMATIONS, STABILITY, AND MATERIALS. INTERACTIONS

6. DEFECTS, DIFFUSION, AND RADIATION EFFECTS

7. ENGINEERING MATERIALS SCIENCE

8. MECHANICAL PROPERTIES

9. THERMODYNAMICS AND ELECTROCHEMISTRY
LOCATION

DATE

ARGONNE NATIONAL LABORATORY

LAWRENCE BERKELEY LABORATORY

MARCH 16-18

OAK RIDGE NATIONAL LABORATORY

APRIL 13-15

BROOKHAVEN NATIONAL LABORATORY

APRIL 18-20

LAWRENCE BERKELEY LABORATORY

APRIL 18-20

OAK RIDGE NATIONAL LABORATORY

APRIL 27-29

CAK RIDGE NATIONAL LABORATORY

MAY 2-4

ARGONNE NATIONAL LABORATORY

MAY 5-7

ARGONNE NATIONAL LABORATORY
MAY $18-20$ 
MATERIALS RESEARCH REOU!RED

HIGH STRENGTH HIGH TEMPERATURES RADIATION EFFECTS CORROSION, EROSION CATALYSTS

POLYMERS

INSULATORS

ELECTROLYTES

COATINGS, CLADDINGS

SUPERCONDUCTORS

METAL HYDRIDES

COMPOSITES

AMORPHOUS

CEMENTS

SEMICONDUCTORS

FLUIDS

ALLOYS

CERAMICS

\begin{tabular}{|c|c|c|c|c|c|c|c|}
\hline \multirow[b]{2}{*}{ FOSSIL } & \multirow[b]{2}{*}{ Fission } & \multirow[b]{2}{*}{ Fusina } & \multicolumn{3}{|c|}{ ENERGY TECHNOLOGIES } & & \\
\hline & & & SOLAR & GEOTHERMAL & STORAGE & CONSERVATION & $\begin{array}{l}\text { ENVIRONMENT } \\
\text { AND SAFETY }\end{array}$ \\
\hline$x$ & $\mathbf{x}$ & $x$ & & $x$ & & . & $x$ \\
\hline $\mathrm{x}$ & $x$ & $x$ & $\mathrm{x}$ & $x$ & $x$ & $x$ & \\
\hline$x$ & $x$ & $\mathrm{x}$ & & & & & $\mathrm{x}$ \\
\hline$x$ & $x$ & $x$ & $x$ & $x$ & $x$ & $x$ & $x$ \\
\hline \multirow[t]{2}{*}{$x$} & & $\therefore$ & $x$ & . & $x$ & $x$ & $x$ \\
\hline & & & $\mathbf{x}$ & & & $x$ & $x$ \\
\hline \multirow[t]{2}{*}{$x$} & & $\mathrm{x}$ & $x$ & 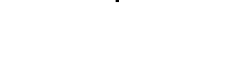 & $x$ & $x$ & $x$ \\
\hline & & & & & $x$ & $x$ & \\
\hline$x$ & $x$ & $x$ & $x$ & $x$ & & $x$ & \\
\hline \multirow[t]{2}{*}{$x$} & & $x$. & & & $x$ & $x$ & \\
\hline & & $x$ & & & $x$ & & $x$ \\
\hline \multirow[t]{2}{*}{$\mathrm{x}$} & $x$ & & $x$ & & & $x$ & \\
\hline & & $x$ & $x$ & & $x$. & $x$ & $x$ \\
\hline \multirow[t]{2}{*}{$x$} & & & & $x$ & & & $x$ \\
\hline & & & $x$ & & & $x$ & $x$ \\
\hline $\mathrm{x}$ & $x$ & $x$ & $x$ & $x$ & $x$ & & $x$ \\
\hline$x$ & $x$ & $x$ & & $x$ & & & $x$ \\
\hline$x$ & $x$ & $x$ & $x$ & & $x$ & $x$ & $x$ \\
\hline
\end{tabular}




\begin{tabular}{|c|c|c|c|c|c|c|}
\hline \multirow[b]{2}{*}{$\begin{array}{l}\text { MATERIALS } \\
\text { RESEARCH } \\
\text { REQUIRED }\end{array}$} & \multicolumn{6}{|c|}{ CRYSTALLLOGRAPHIC INVESTIGATIONS } \\
\hline & $\begin{array}{l}\text { CAYSTALLINE } \\
\text { STRUCTURES }\end{array}$ & $\begin{array}{l}\text { NONCAYSTALLINE } \\
\text { STRUCTURES }\end{array}$ & $\begin{array}{c}\text { SURFACE } \\
\text { PRDPERTIES }\end{array}$ & $\begin{array}{l}\text { DYNAMICAL } \\
\text { PROPERTIES }\end{array}$ & $\begin{array}{l}\text { MAGNETIC } \\
\text { PAOPERTIES }\end{array}$ & $\begin{array}{l}\text { DEFECTS AND } \\
\text { INHOMOGENEITIES }\end{array}$ \\
\hline HIGH STRENGTH & $x$ & $\mathrm{x}$ & & $x$. & & $\mathrm{x}$ \\
\hline HIGH TEMPERATURES & $\mathrm{x}$ & . & $x$ & $x$ & $x$ & $\mathbf{x}$ \\
\hline RADIATION EFFECTS & $x$ & . & $\mathbf{x}$ & $x$ & $x$ & $x$ \\
\hline CORROSION, EROSION & $x$ & $x$ & $x$ & & & $x$ \\
\hline CATALYSTS & $\mathbf{x}$ & $x$ & $x$ & $x$ & $x$ & $\mathrm{x}$ \\
\hline POLYMERS & $x$ & $x$ & $x$ & $x$ & & $x$ \\
\hline INSULATORS & $x$ & & & $x$ & $x$ & $x$ \\
\hline ELECTROLYTES & $x$ & $x$ & & $x$ & & $\mathrm{x}$ \\
\hline COATINGS, CLADDINGS & $x$ & $\mathbf{x}$ & $x$ & & & $x$ \\
\hline SUPERCONDUCTORS & $x$ & $x$ & $x$ & $x$ & $x$ & $x$ \\
\hline METAL HYDRIDES & $x$ & & $x$ & $x$ & $x$ & $x$ \\
\hline COMPOSITES & $x$ & & & & $x$ & $x$ \\
\hline AMORPHOUS & & $x$ & $\mathbf{x}$ & $x$ & $x$ & $x$ \\
\hline CEMENTS & $x$ & $\mathrm{x}$ & & & & $x$ \\
\hline SEMICONDUCTORS. & $\mathbf{x}$ & $x$ & $x$ & $x$ & $x$ & $x$ \\
\hline FLUIDS & & $x$. & & & & $x$ \\
\hline ALLOYS & $\mathbf{x}$ & $\mathrm{x}$. & $x$ & $x$ & $x$ & $x$ \\
\hline CERAMICS & $x$ & & $x$ & & $x$ & $x$ \\
\hline
\end{tabular}


ORNL- DWG 78-14408

OCTAHEDRAL

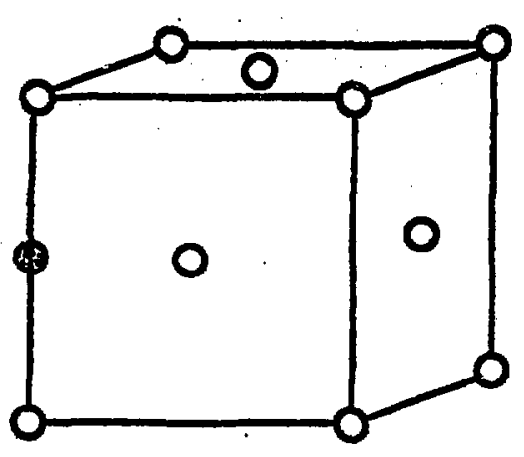

$\langle 100\rangle-S P L I T$

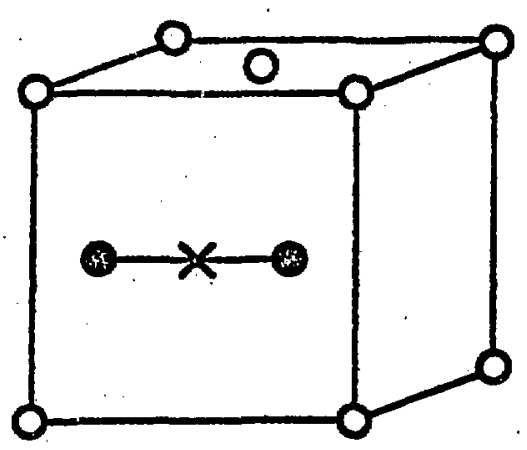

TETRAHEDRAL

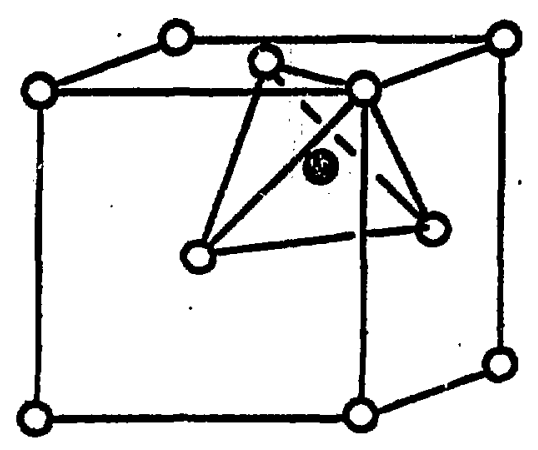

$\langle 119\rangle-S P L I T$

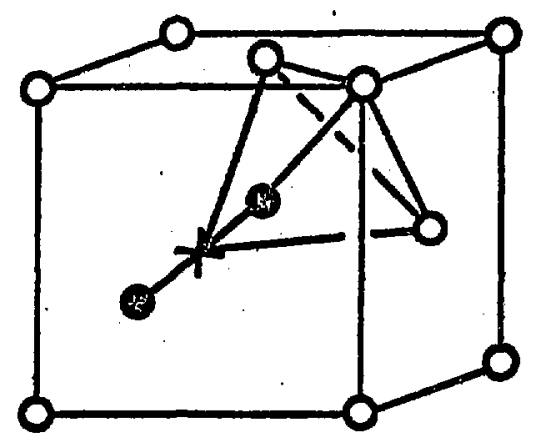

CROWDION

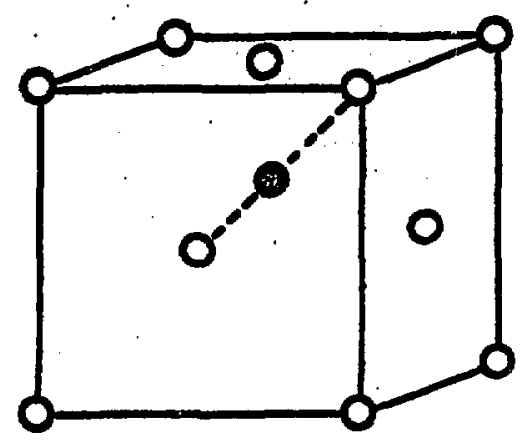

$\langle 110\rangle-$ SPLIT

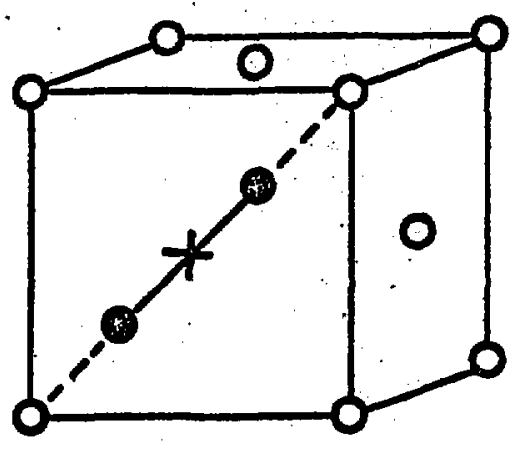

Six Self-Interstitial Configurations in a F.C.C. Lattice.

4 
ORNL-DWG 78-12814
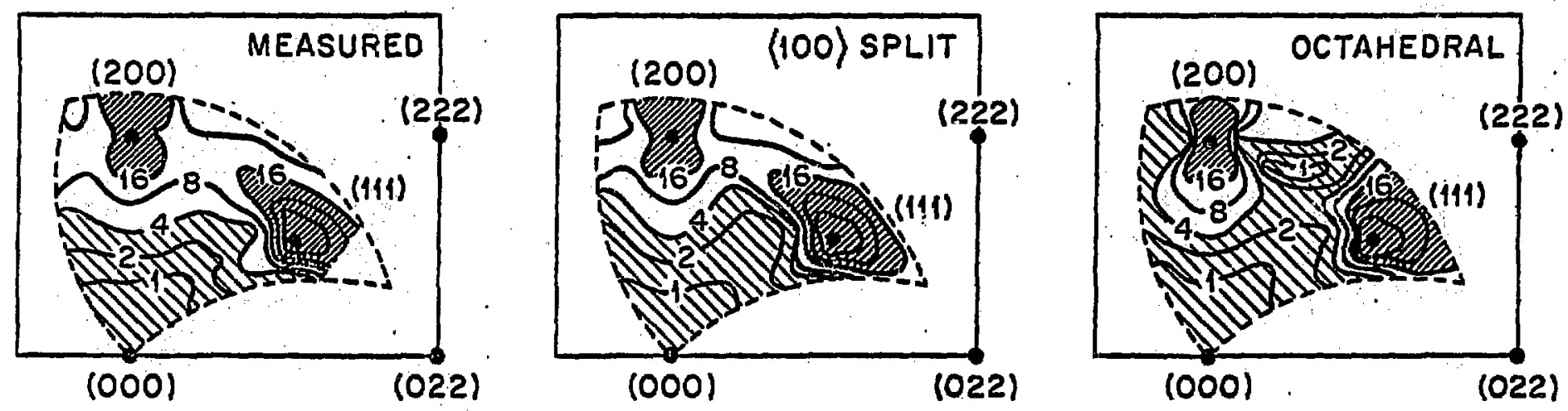

X-RAY DIFFUSE SCATTERING FROM INTERSTITIALS IN ELECTRON IRRADIATED COPPER AT $4^{\circ} \mathrm{K}$ 

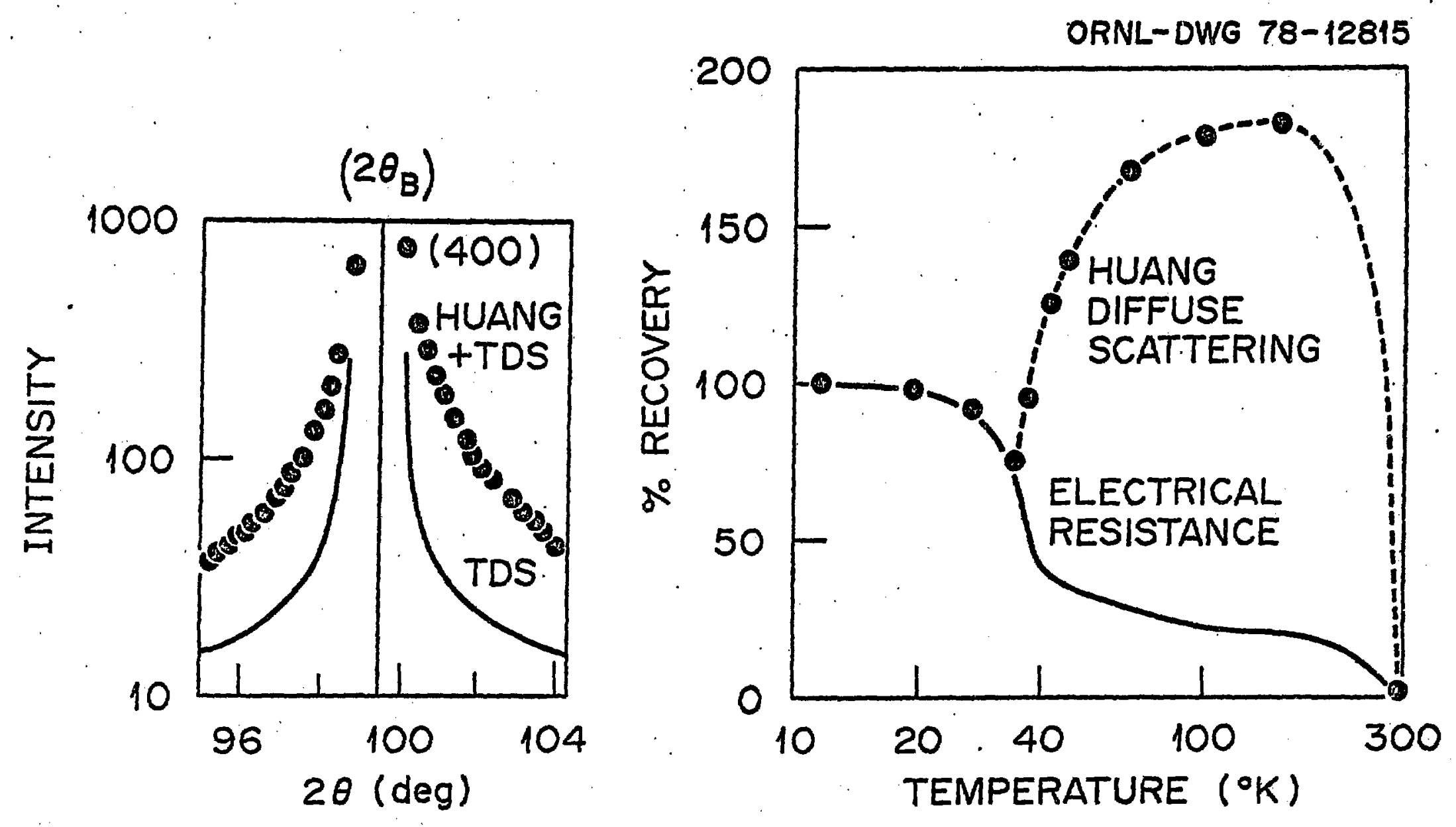

HUANG SCATTERING FROM INTERSTITIALS AND CLUSTERS IN ELECTRON IRRADIATED ALUMINUM AT $4{ }^{\circ} \mathrm{K}$ 


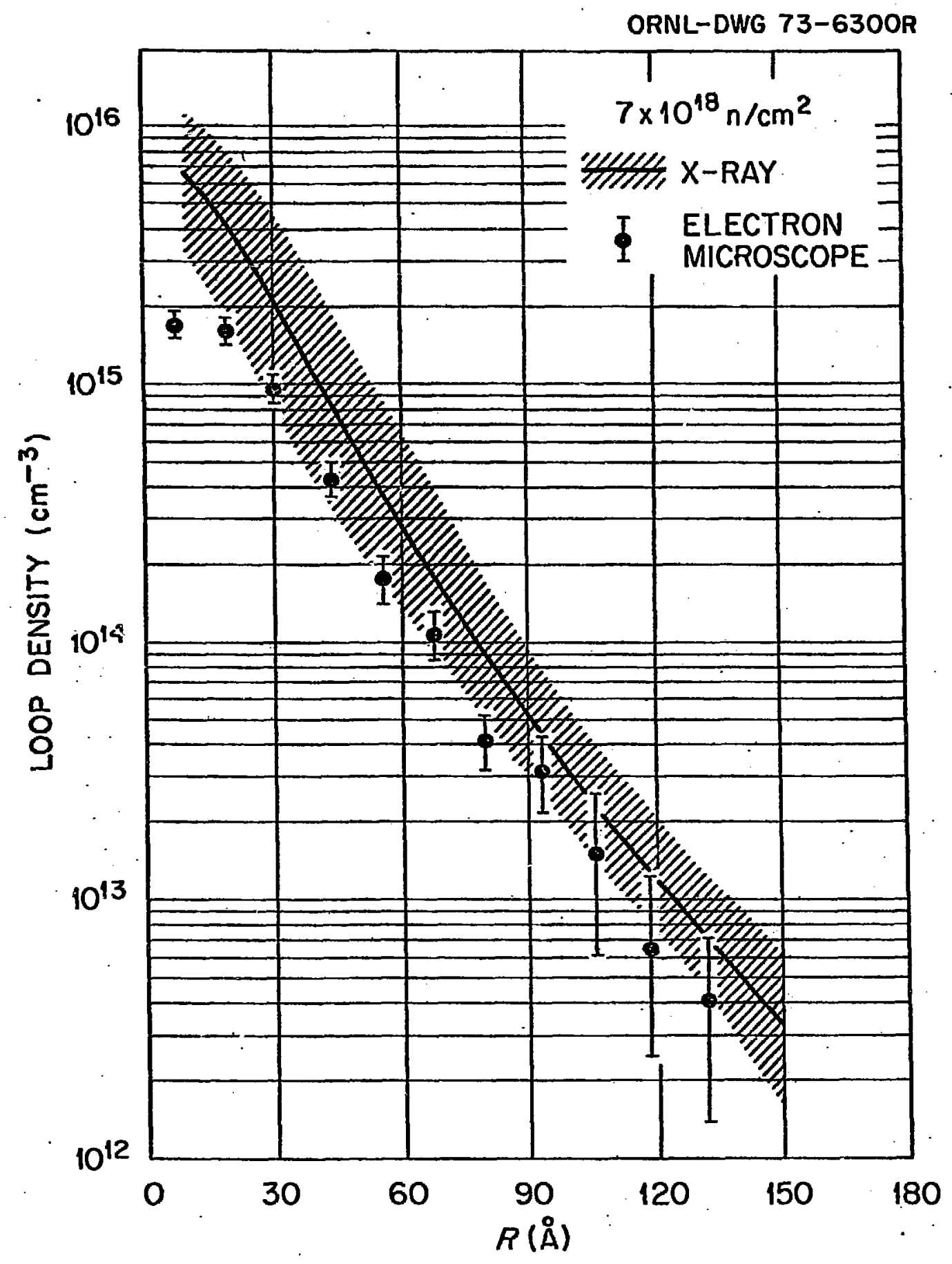

Dislocation Loops in Copper Neutron Irradiated at $316^{\circ} \mathrm{K}$. 


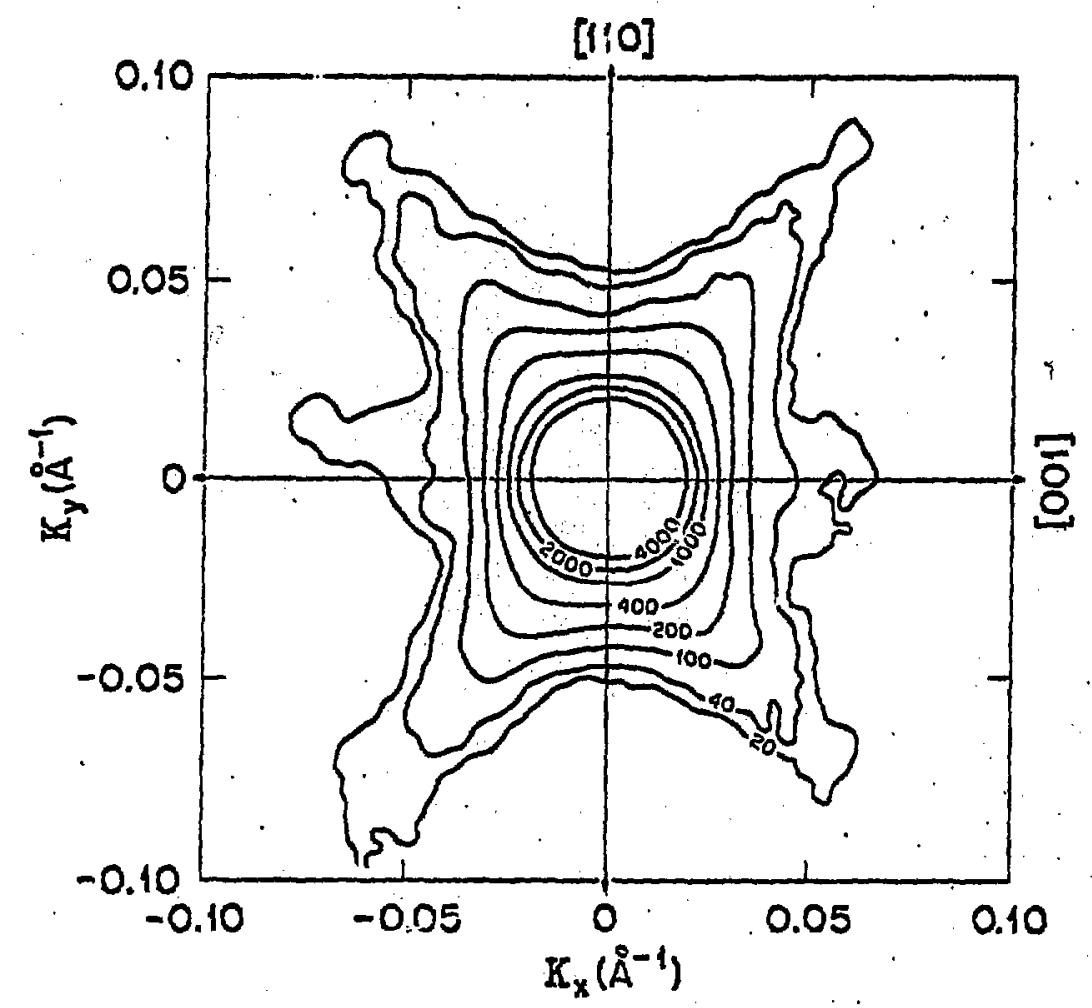

ORNL-DWG 7B-12813

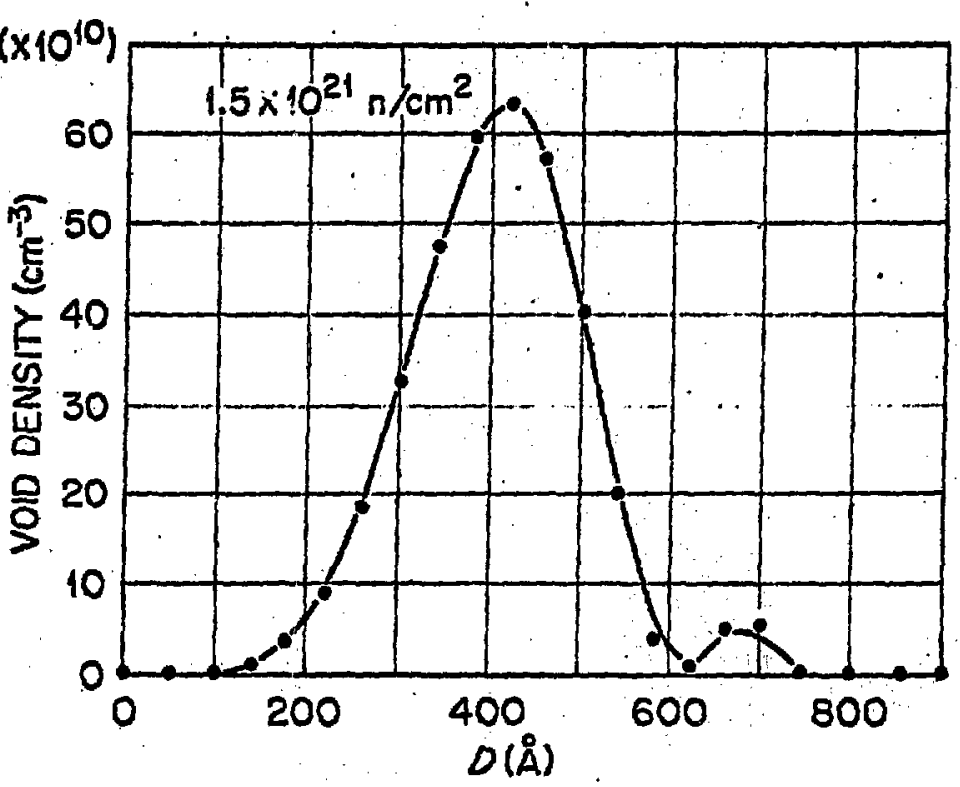

S.A.N.S. AND SIZE DISTRIBUTION OF VOIDS IN ALUMINUM NEUTRON IRRADIATED AT $355^{\circ} \mathrm{K}$ 


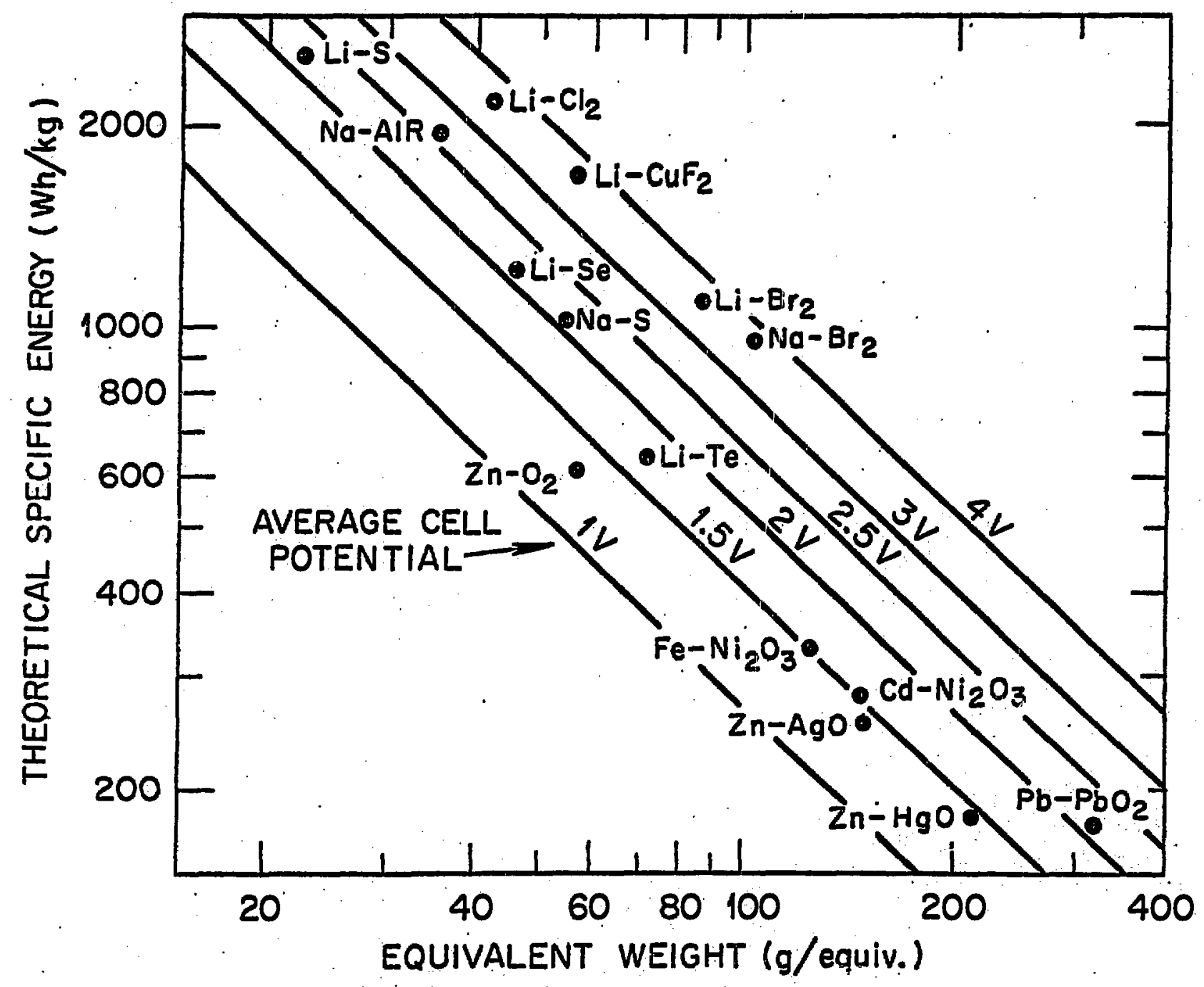

THEORETICAL SPECIFIC ENERGY OF ELECTROCHEMICAL COUPLES. 


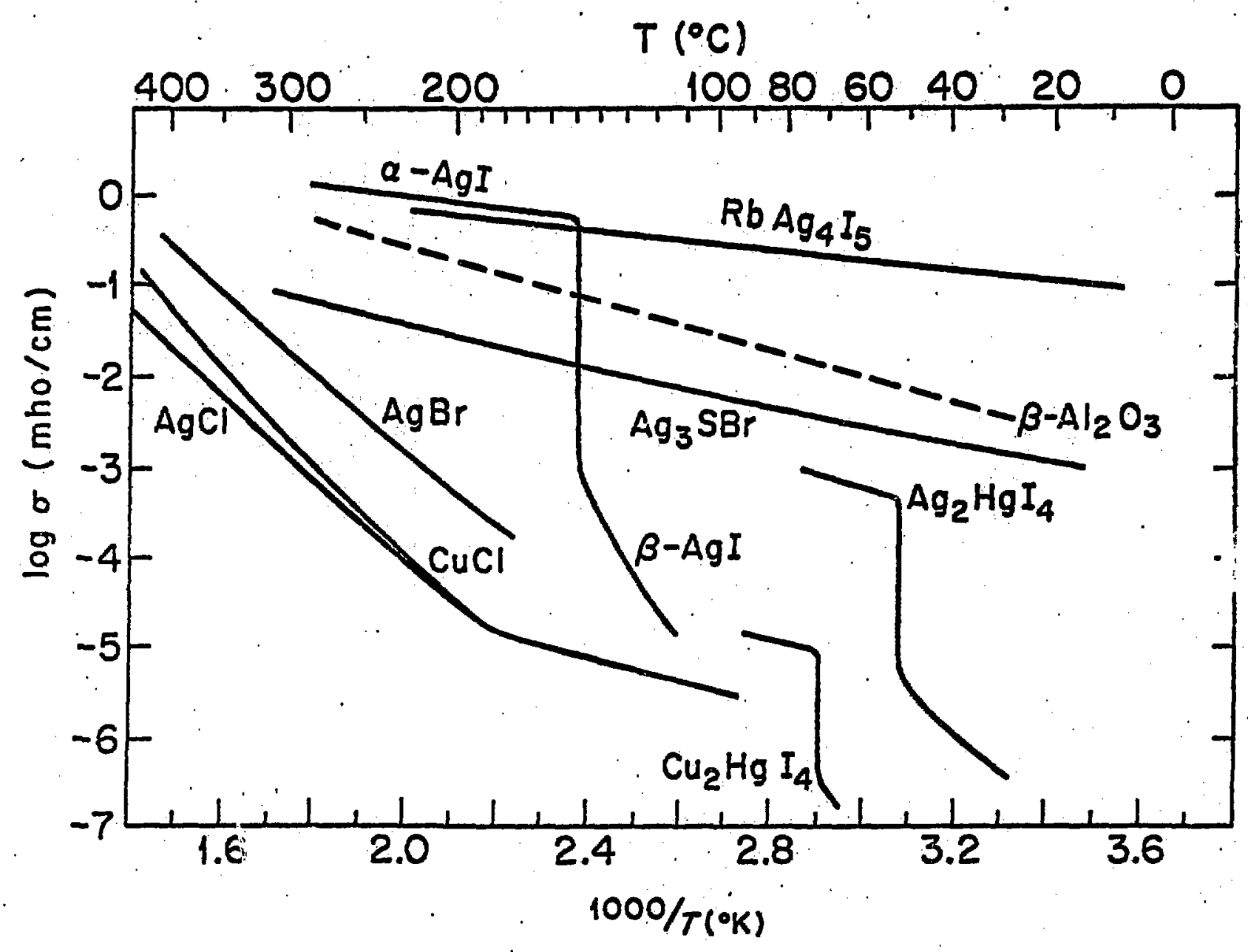

IONIC CONDUCTIVITY OF VARIOUS SUPERIONIC CONDUCTORS 
ORNL-DWG 78-12605

$\mathrm{Na}_{2} \mathrm{O} \cdot 11 \mathrm{Al}_{2} \mathrm{O}_{3}$ (idealized)

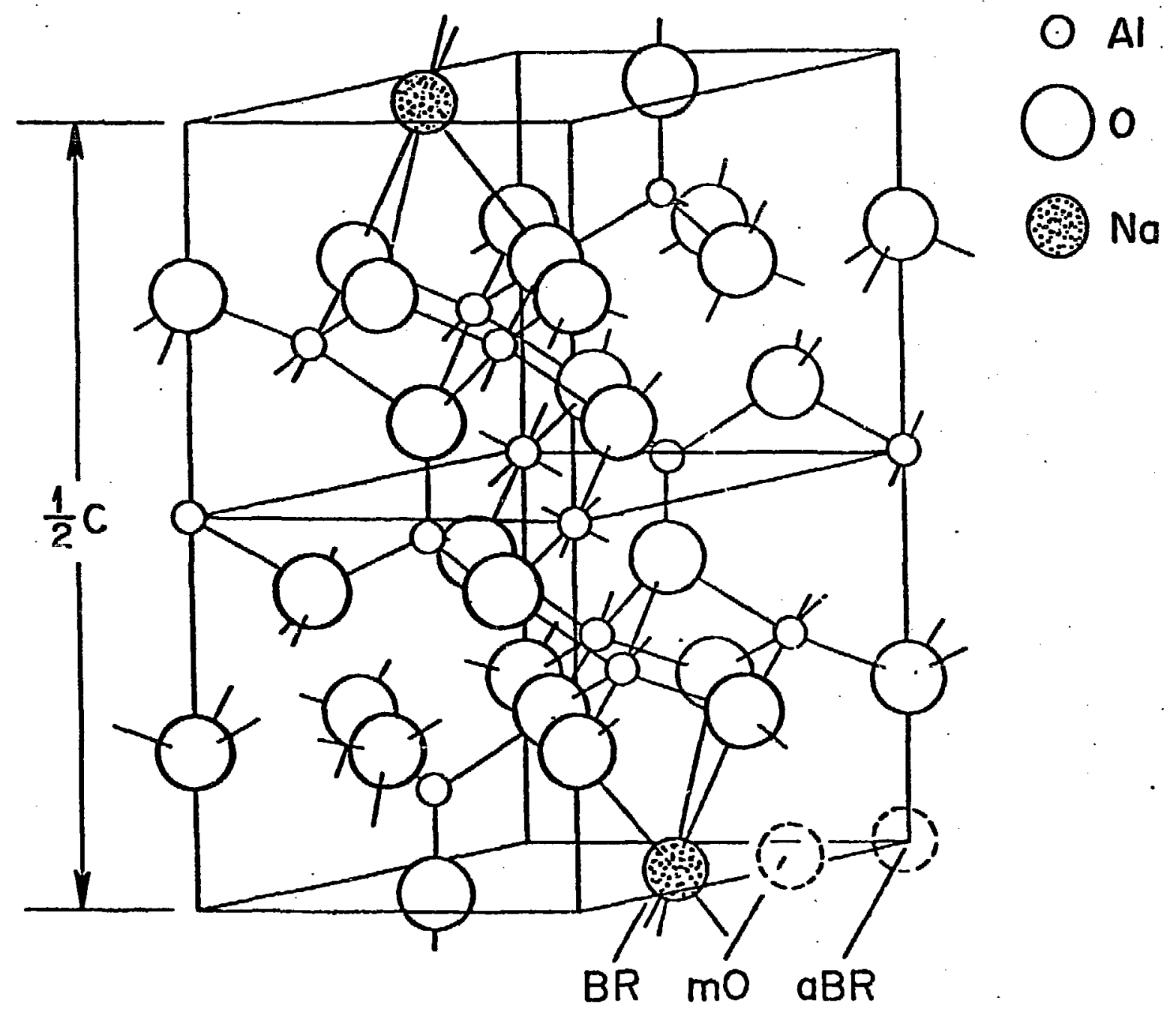

SPINEL BLOCK IN $\beta$-ALUMINA 
ORNL-DWG 78-12606

0.5

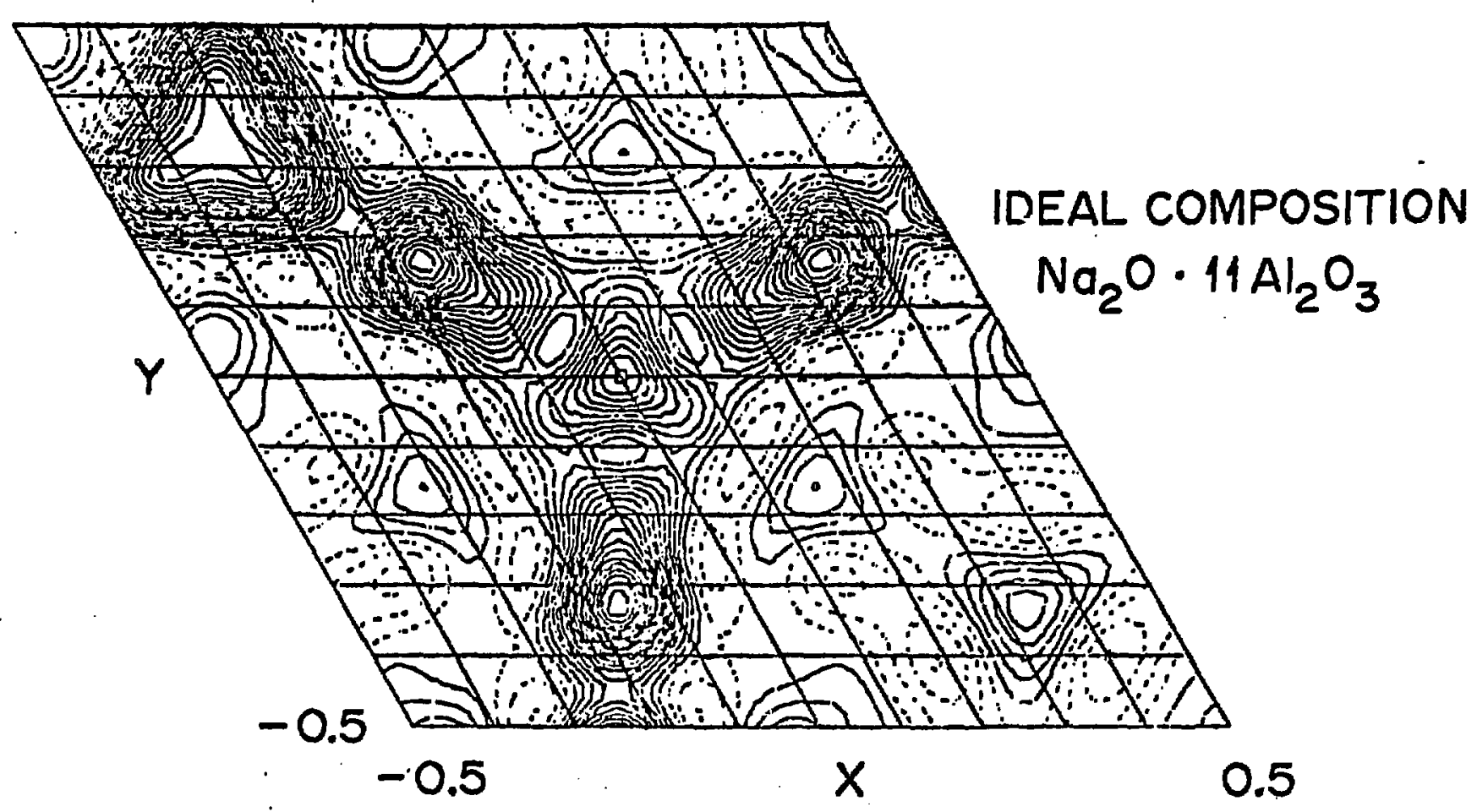

SODIUM DISTRIBUTION IN CONDUCTION PLANE OF Na $\beta$-ALUMINA AT $20^{\circ} \mathrm{C}$ 
ORNL-DWG 78-12607

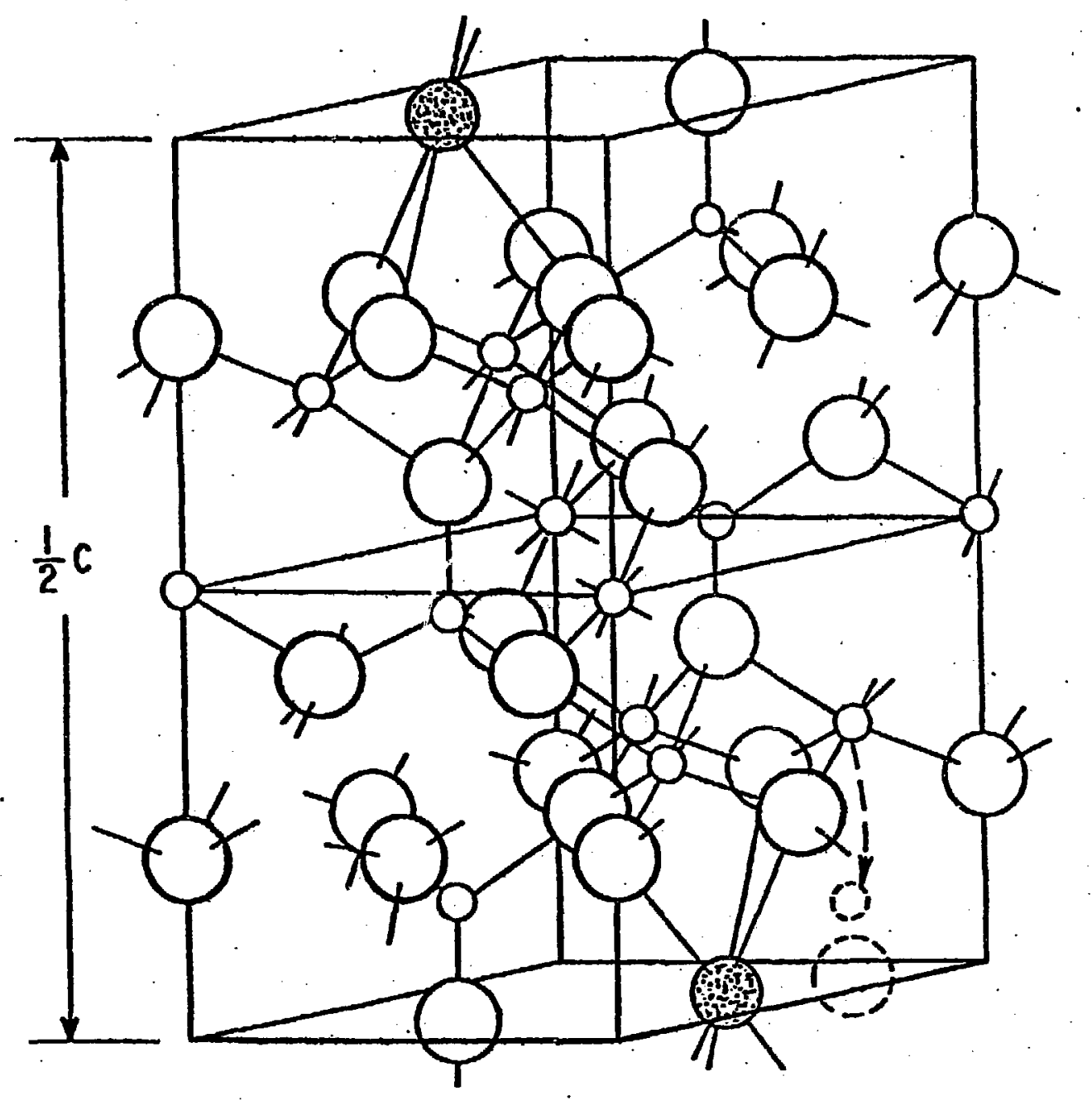

O Al

C 0

Na

FRENKEL DEFECT IN SPINEL

BLOCK OF $\beta$-ALUMINA 


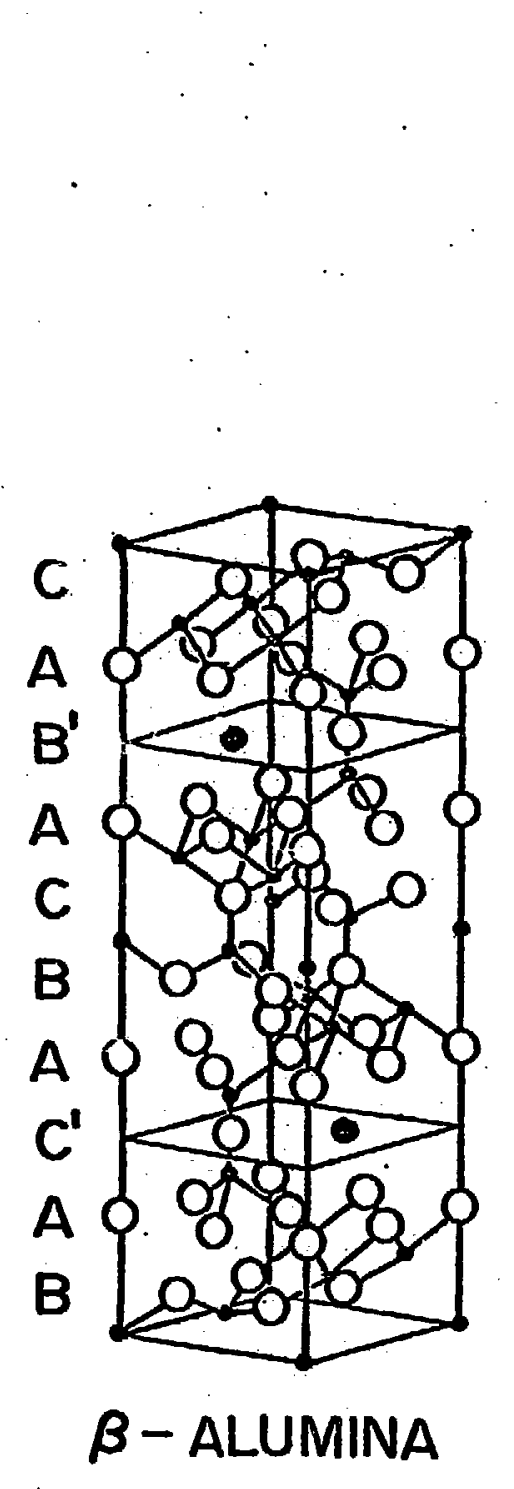

ORNL-DWG 78-12608

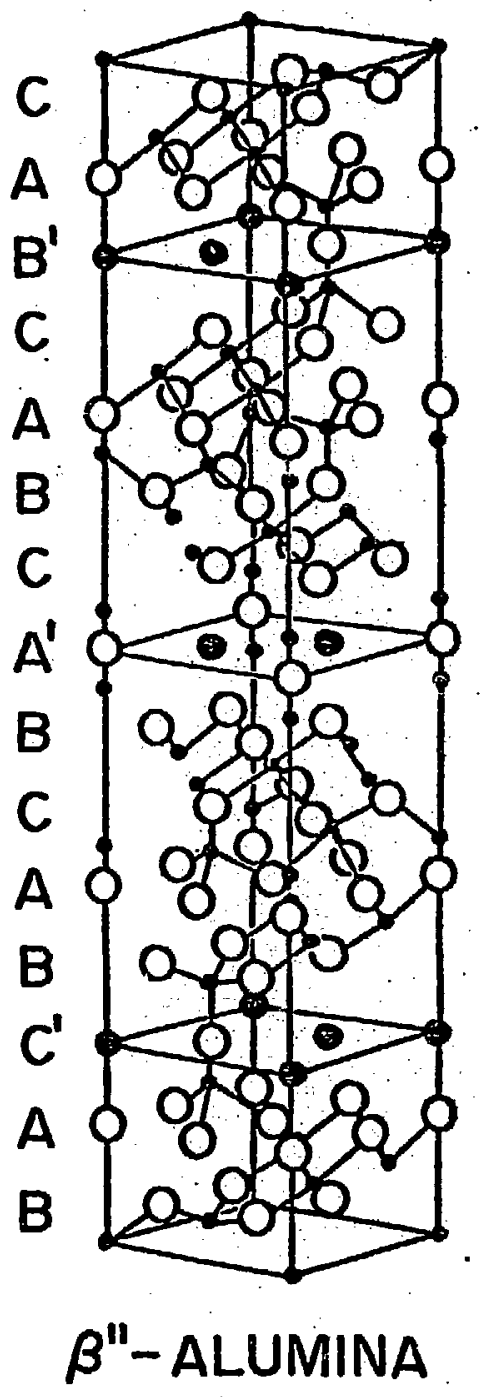

$$
\begin{gathered}
\text { STRUCTURES OF } \\
\beta \text {-ALUMINA AND } \beta^{\prime \prime} \text {-ALUMINA } \\
\text { (idealized) }
\end{gathered}
$$




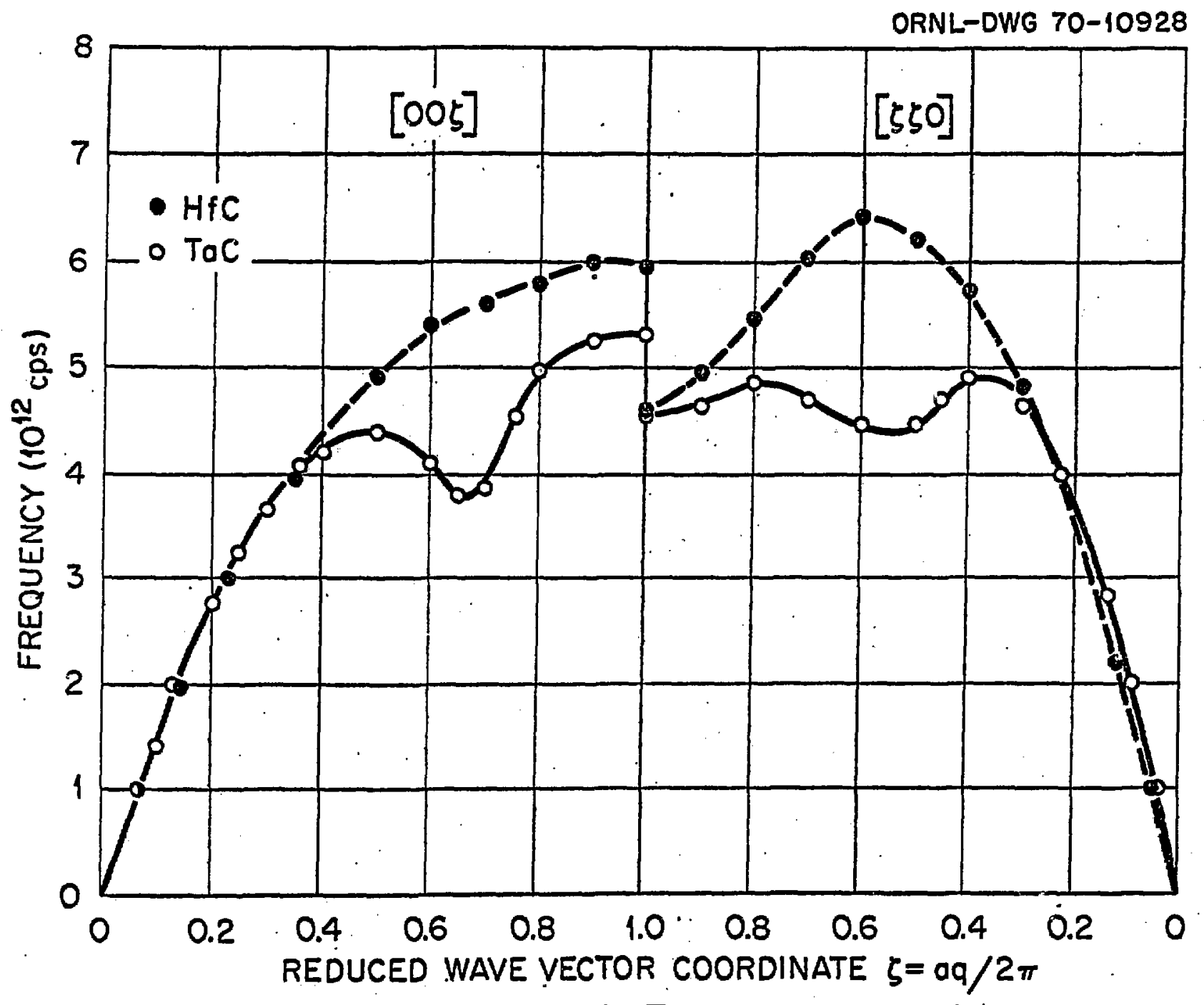

Longitudinal Acoustic Modes in Tantalum and Hafnium Carbide.

15 


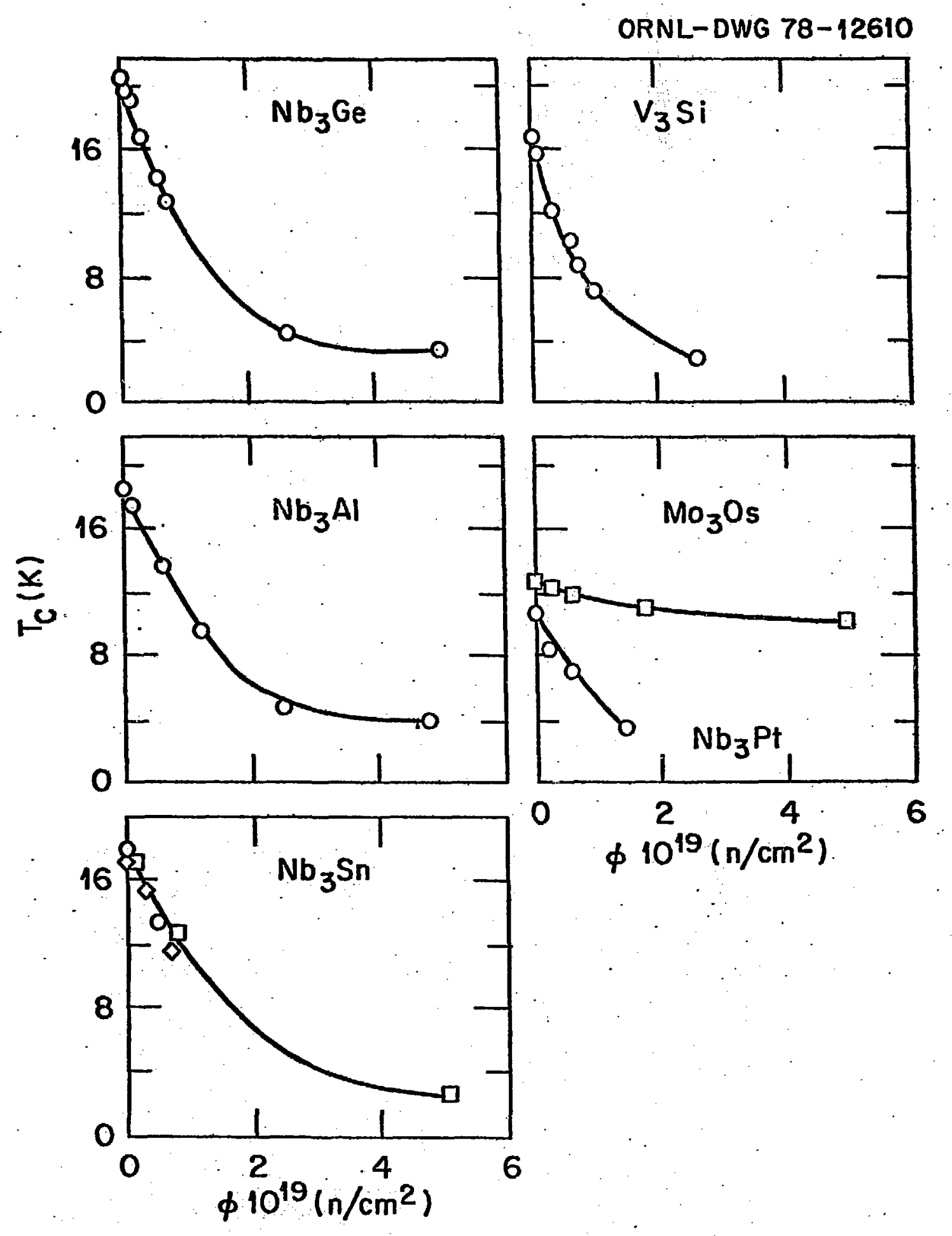

VARIATION OF TC IN A-15 COMPOUNDS WITH NEUTRON FLUENCE $(E>1 \mathrm{MeV})$ 


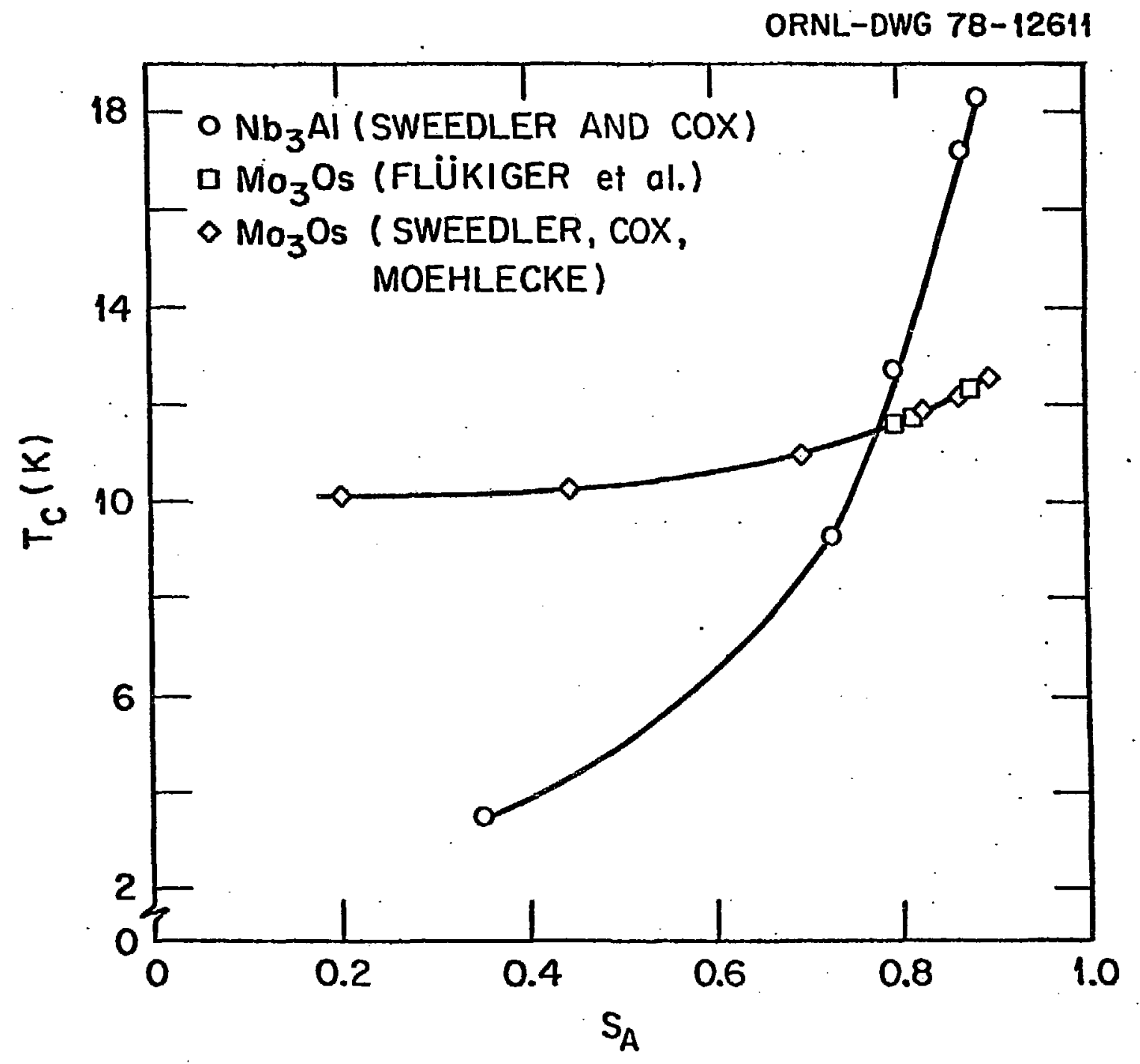

VARIATION OF $T_{C}$ WITH LONG RANGE ORDER 
ORNL-DWG 78-12612
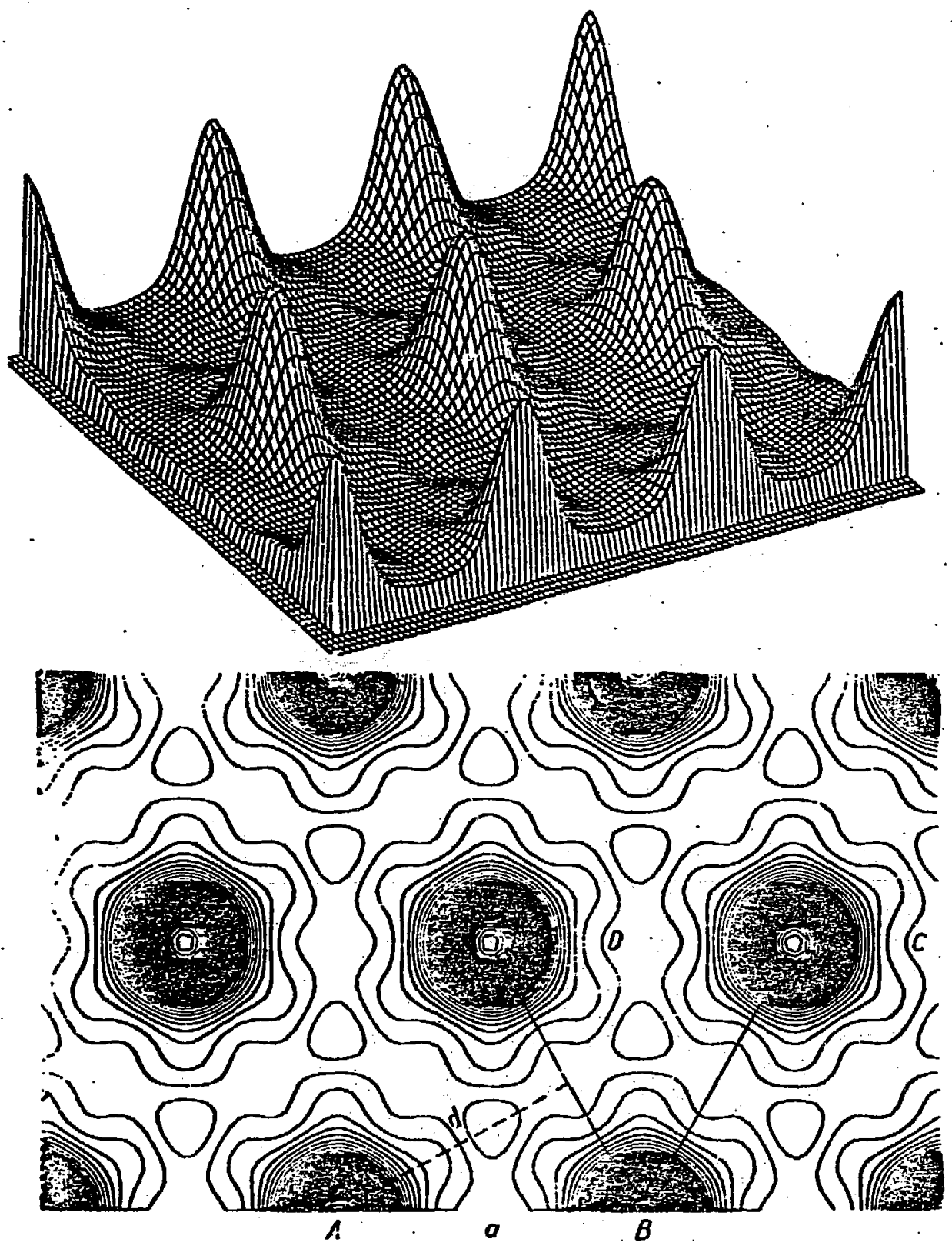

MAGNETIC FIELD DISTRIBUTION IN
SUPERCONDUCTING NIOBIUM 


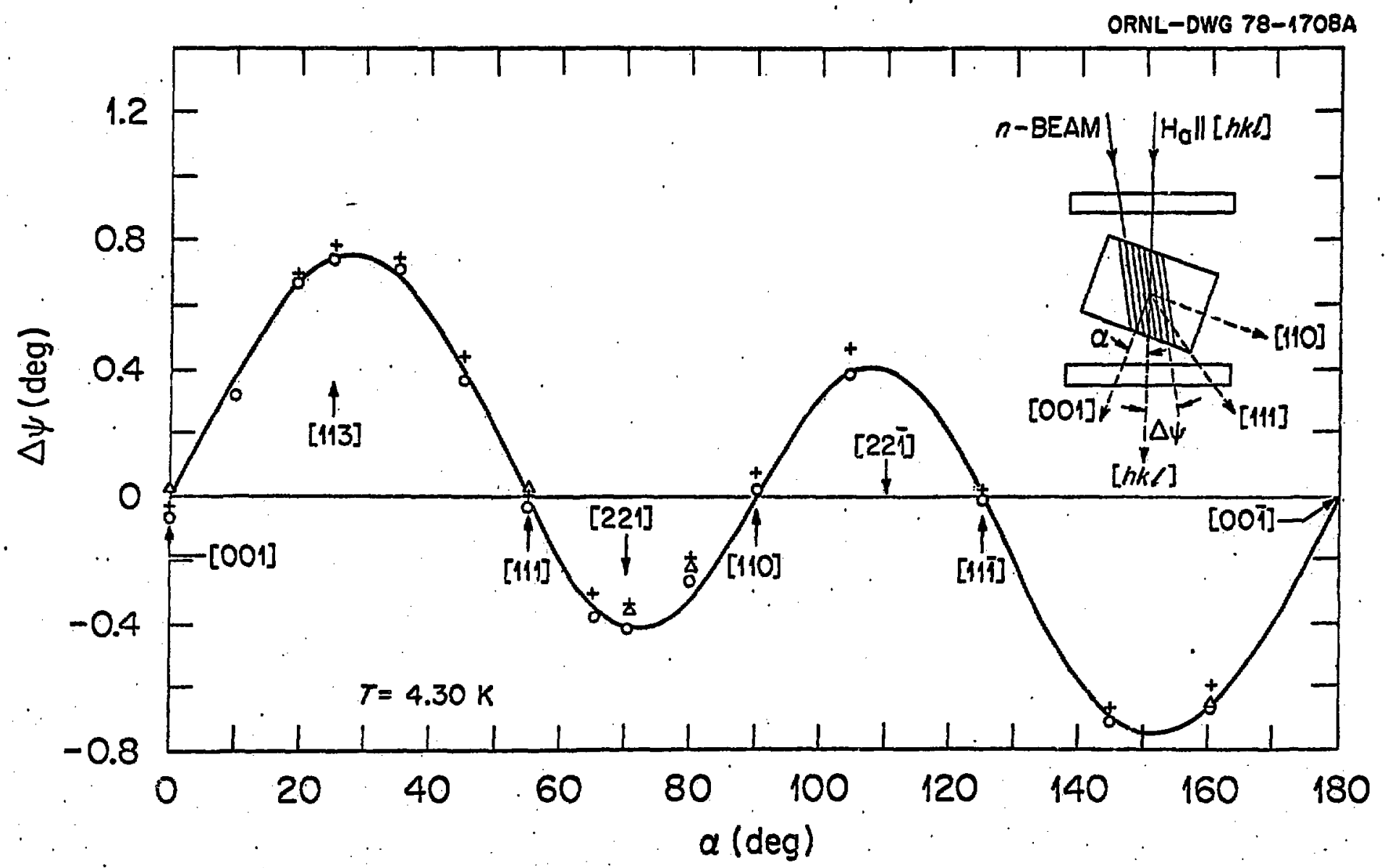

Misalignment Angle $\Delta \psi$ vs $\alpha$ in (1T0) Plane

19 


\section{TYPES OF CATALYSTS}

class of MATERIALS

METALS

ALLOYS

BORIDES

OXIDES

SULFIDES

ZEOLITES

ORGANOMETALLIC COMPLEXES

HOMOGENEOUS

\section{EXAMPLES}

Pt, Pd, Ni

NiCu, PtAu, Niw, RuCu, ZrPt

$\mathrm{Ni}_{3} \mathrm{~B}, \mathrm{Mo}_{2} \mathrm{BC}, \mathrm{Co}_{21} \mathrm{Hf}_{2} \mathrm{~B}_{6}$

$\mathrm{CrAl}_{2} \mathrm{O}_{4}, \mathrm{MgAl}_{2} \mathrm{O}_{4}, \mathrm{Mg}_{2} \mathrm{Mo}_{3} \mathrm{O}_{8}$

$\mathrm{BaRuO}_{3}, \mathrm{TiO}_{2} \cdot \mathrm{SiO}_{2}$

VS, $V_{5} S_{8}, \operatorname{Cov}_{2} S_{4}$

$\mathrm{La}_{4} \mathrm{NiS}_{7} \cdot \mathrm{Al}_{x} \mathrm{Mo}_{2} \mathrm{~S}_{4}$

$\mathrm{Ba}\left(\mathrm{Al}_{2} \mathrm{Si}_{3} \mathrm{O}_{10}\right) \cdot 4 \mathrm{H}_{2} \mathrm{O}$

(K, $\mathrm{Na})_{5} \mathrm{Si}_{11} \mathrm{Al}_{5} \mathrm{O}_{32} \cdot 10 \mathrm{H}_{2} \mathrm{O}$

$\mathrm{Ca}\left(\mathrm{Al}_{2} \mathrm{Si}_{4}\right) \mathrm{O}_{12} \cdot 6 \mathrm{H}_{2} \mathrm{O}$

$\mathrm{Pt}_{3}\left[\mathrm{CN}\left(\mathrm{C}_{4} \mathrm{H}_{9}\right)\right]_{6}, \mathrm{Rh}_{13}(\mathrm{CO})_{24} \mathrm{H}_{3}$,

$A u_{11}\left[P\left(C_{6} H_{5}\right)_{3}\right]_{7} I_{3}$

$\mathrm{Co}_{2}(\mathrm{CO})_{8}$

$\mathrm{C}_{90} \mathrm{H}_{148} \mathrm{O}_{72} \cdot 25 \mathrm{H}_{2} \mathrm{O}$

20 
ORNL-DWG 76-17133 A

\section{Au (110) SURFACE}
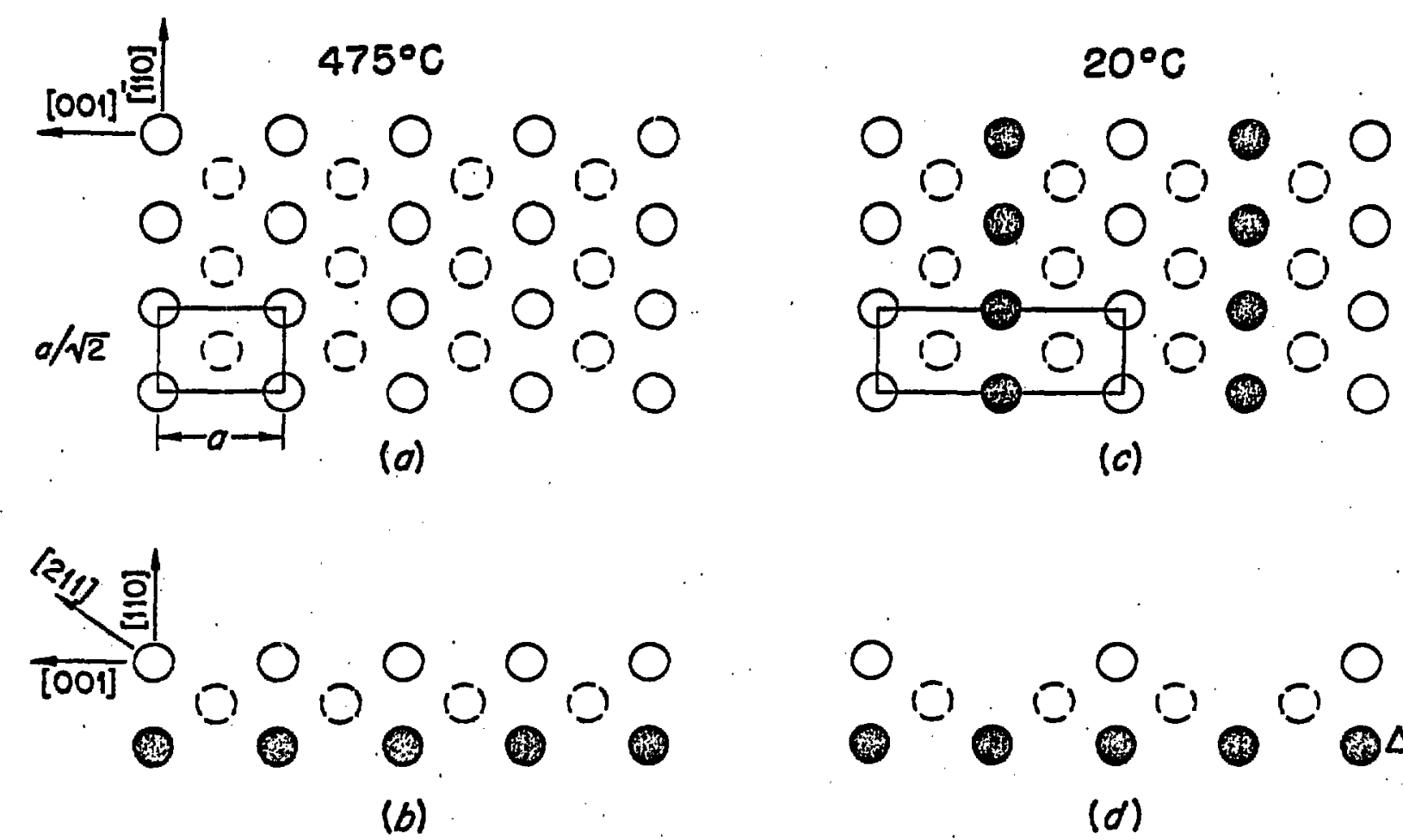

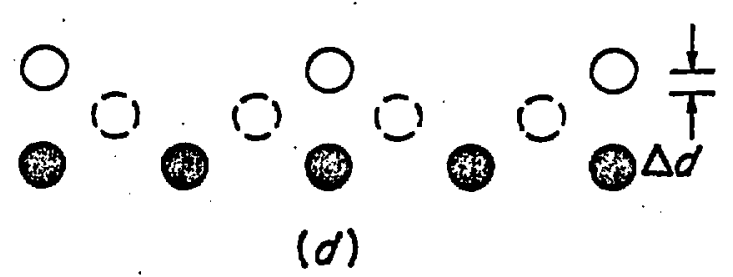

OFIRST LAYER G SECOND LAYER

7. THIRD LAYER

21 


$$
\text { ORNL-DWG 78-12614 }
$$

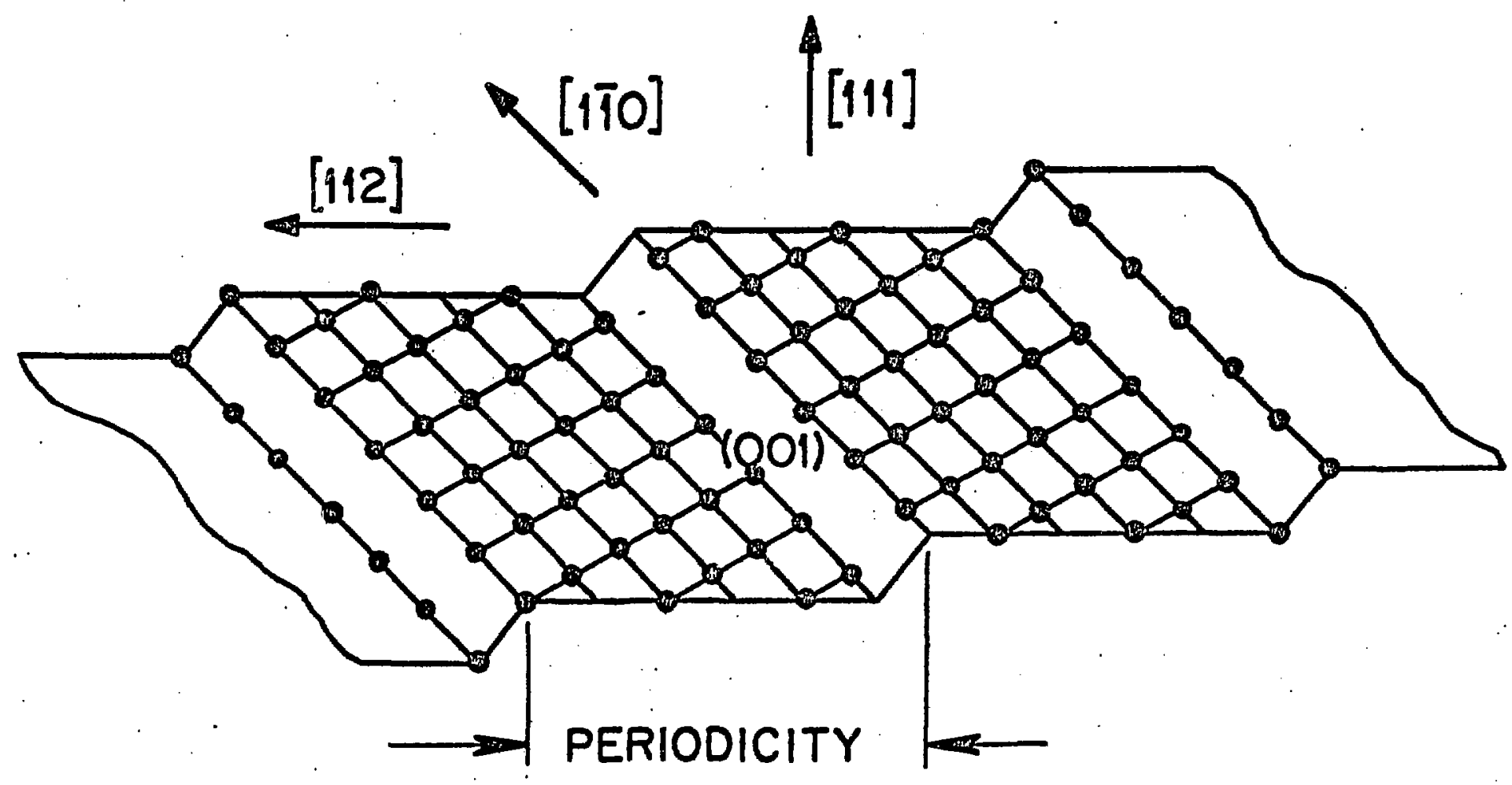

SCHEMATIC REPRESENTATION OF A STEPPED SURFACE. 
ORNL DWG 78.12616

Particle Sizes $\langle L\rangle_{h \dot{k} l}$ in the $\langle h k l\rangle$ Directions and Percentage Exposed

\begin{tabular}{lcccccc}
\hline Catalyst & $\begin{array}{c}\langle L\rangle_{111} \\
(\AA)\end{array}$ & $\begin{array}{c}\langle L\rangle_{100} \\
(\AA)\end{array}$ & $\begin{array}{c}\langle L\rangle_{110} \\
(\AA)\end{array}$ & $\begin{array}{c}\langle L\rangle_{311} \\
(\AA)\end{array}$ & $\begin{array}{c}D_{x} \\
(\%)\end{array}$ & $\begin{array}{c}D_{h} \\
(\%)\end{array}$ \\
\hline $\begin{array}{l}7.1-\mathrm{SiO}_{2} \text {-PtCl-S } \\
(1)\end{array}$ & 131 & 82 & 108 & 81 & 10 & 7.1 \\
$(2)$ & 111 & 75 & - & - & 12 & 7.1 \\
$21.5-\mathrm{SiO}_{2}$-I onX-L & & & & & & \\
$(1)$ & 49 & 43 & 45 & 47 & 25 & 21.5 \\
$(2)$ & 48 & 43 & 45 & 47 & 25 & - \\
$27-\mathrm{SiO}_{2}-$ IonX-S & 43 & 39 & 42 & 31 & 27 & 27.3 \\
$(1)$ & 40 & 39 & 39 & 39 & 29 & - \\
$(2)$ & & & & & & \\
$40-\mathrm{SiO}_{2}$-PtCl-S & 30 & 26 & 22 & 20 & 44 & 39.8 \\
$(1)$ & 25 & 23 & - & - & 47 & \\
$(2)$ & & & & & & \\
\hline
\end{tabular}




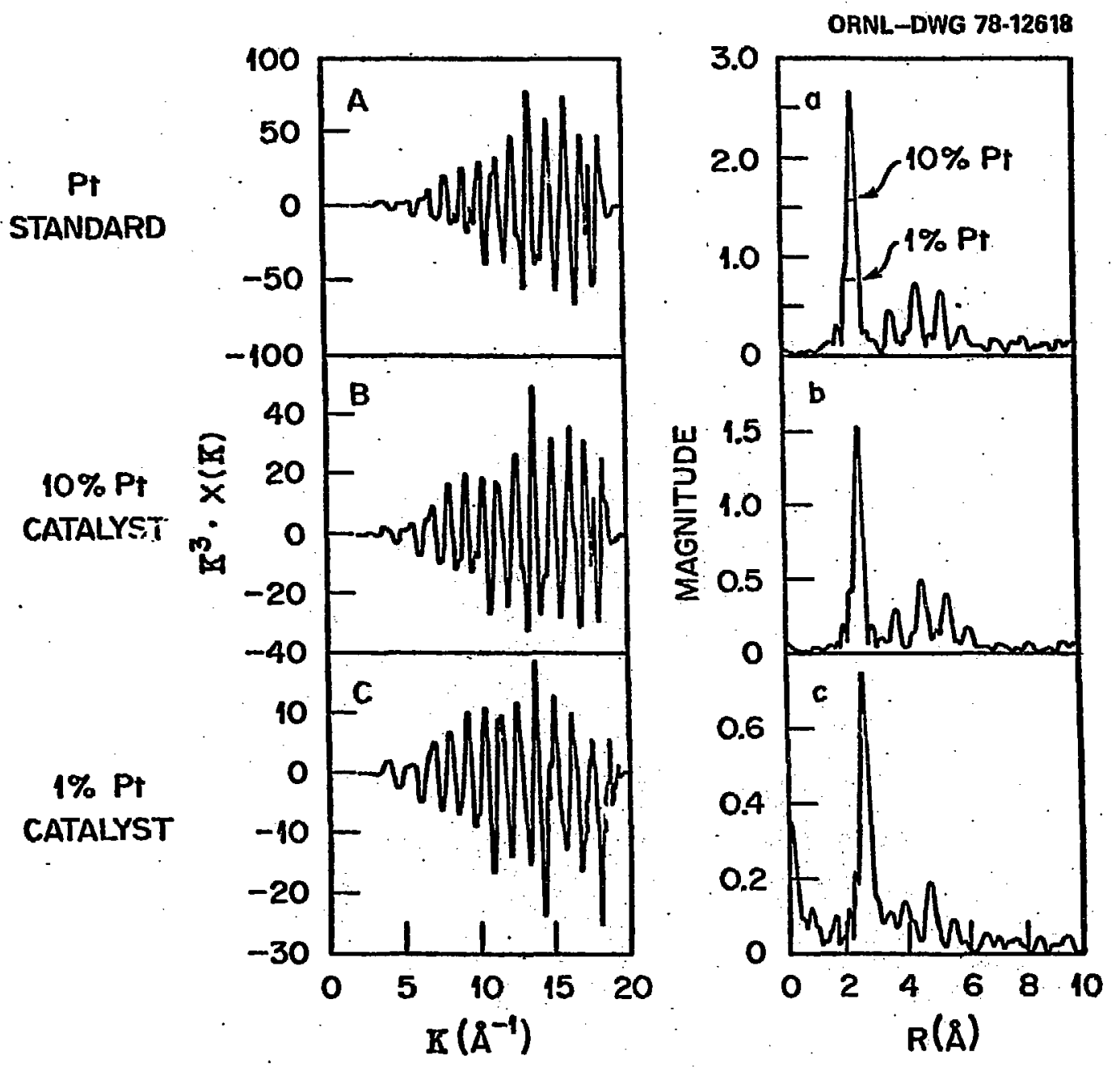

NORMALIZED EXAFS DATA FOR Pt 
ORNL-DWG 78-14720

NEW DIRECTIONS FOR CRYSTALLOGRAPHIC RESEARCH

1. CONTROLLED ENVIRONMENTAL EFFECTS

2. TIME-DEPENDENT PHENOMENA

3. EFFECTS OF EXTERNAL TRANSIENT PHENOMENA

4. GRAIN BOUNDARY PROPERTIES

5. HIGH RESOLUTION ANALYTICAL MICROSCOPY

6. EFFECTS OF GASES ON VOID FORMATION

7. REAL-TIME MEASUREMENTS OF DEFECT DYNAMICS

8. STRUCTURE AND DYNAMICS OF SURFACES AND OVERLAYERS

9. INTERACTIIONS BETWEEN SUPPORTED CATALYSTS AND SUBSTRATES

10. HIGH RESOLUTION INELASTIC X-RAY SCATTERING

11. MACROMOLECULAR CRYSTALLOGRAPHY

12. INHOMOGENEITIES IN GLASSES 